\title{
Global Critical Materials Markets: An Agent-based Modeling Approach
}

Matthew Riddle, ${ }^{\mathrm{a},{ }^{*}}$ Charles M. Macal, ${ }^{\mathrm{a}}$ Guenter Conzelmann, ${ }^{\mathrm{a}}$ Todd E. Combs, ${ }^{\mathrm{a}}$ Diana Bauer, ${ }^{\text {b Fletcher Fields }}{ }^{\mathrm{b}}$

a Decision and Information Sciences Division, Argonne National Laboratory,9700 South Cass Avenue, Argonne, IL, USA 60439

${ }^{b}$ Office of Energy Policy and Systems Analysis, U.S. Department of Energy, 1000 Independence Avenue, SW, Washington, DC, USA 20585

* Corresponding author. Tel.: +1 4135597551.

E-mail address: meriddle@anl.gov 
Global Critical Materials Markets: An Agent-based Modeling Approach 


\section{Contents}

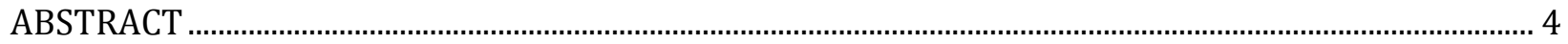

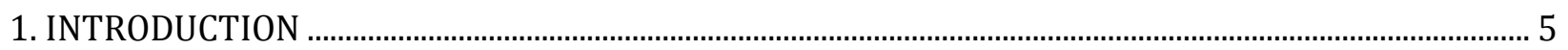

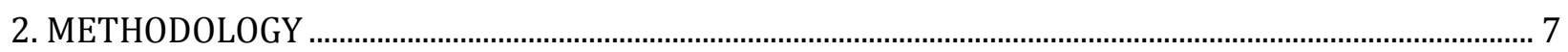

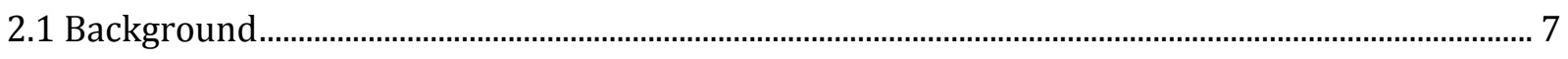

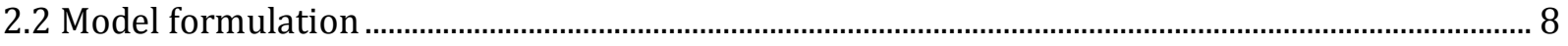

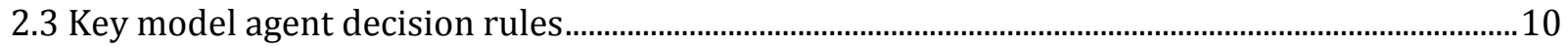

2.3.1 Price forecasting.....................................................................................................................

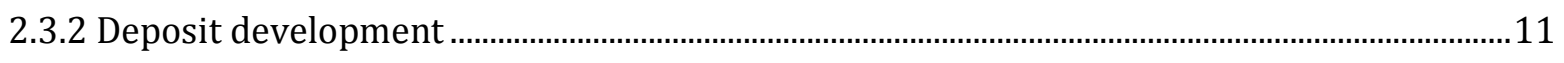

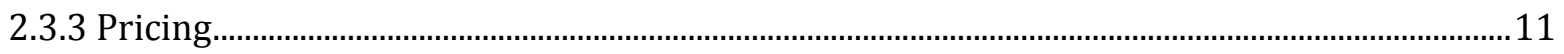

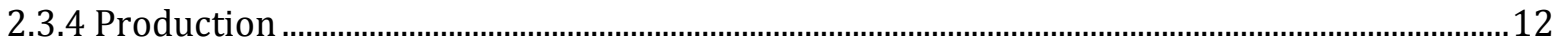

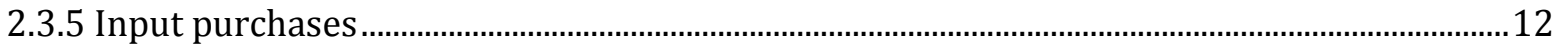

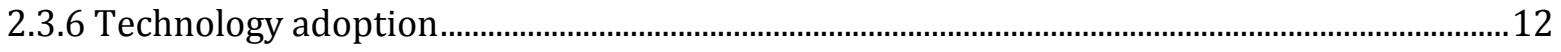

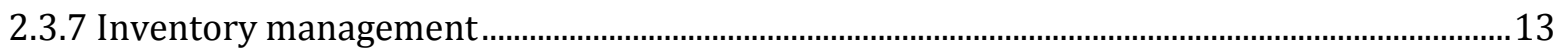

2.3.8 Demand response to prices ……………….............................................................................

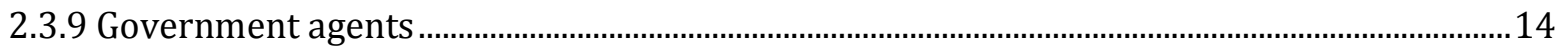

3. BASELINE SCENARIO ASSUMPTIONS AND SETUP ………......................................................................

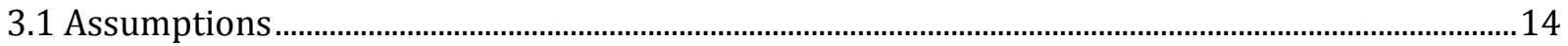

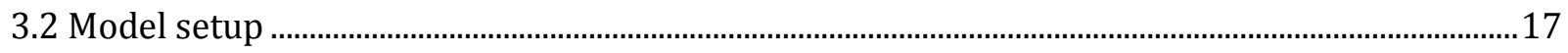

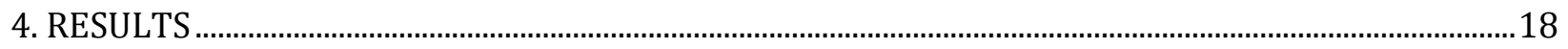

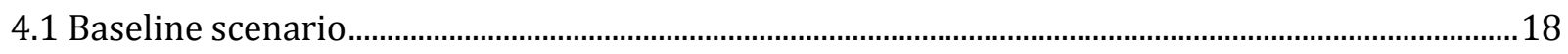

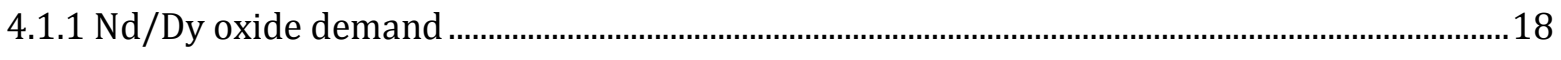

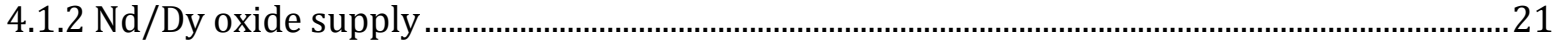

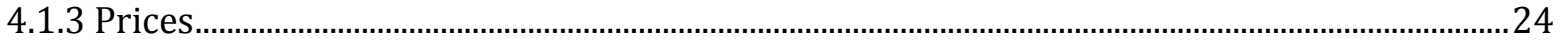

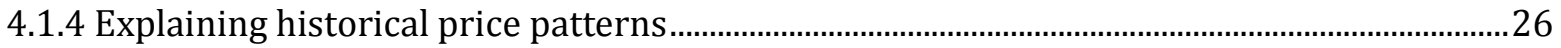

4.1.5 Relationship between Nd and Dy ........................................................................................27

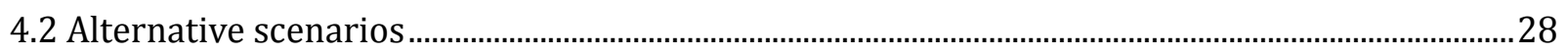

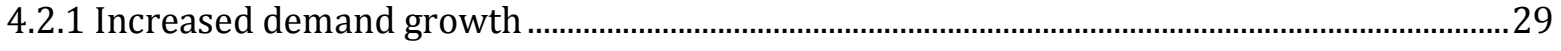

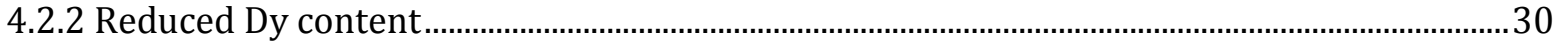

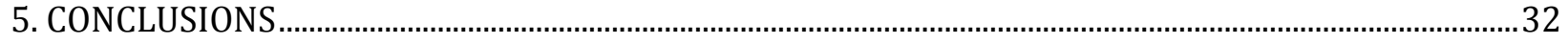

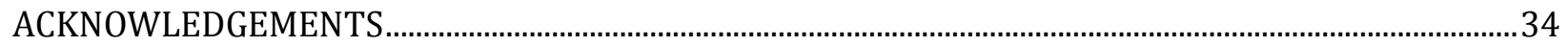




\section{ABSTRACT}

As part of efforts to position the United States as a leader in clean energy technology production, the U. S. Department of Energy (DOE) issued two Critical Materials Strategy reports, which assessed 16 materials on the basis of their importance to clean energy development and their supply risk (DOE, 2010, 2011). To understand the implications for clean energy of disruptions in supplies of critical materials, it is important to understand supply chain dynamics from mining to final product production. As a case study of critical material supply chains, we focus on the supply of two rare earth metals, neodymium ( $\mathrm{Nd}$ ) and dysprosium (Dy), for permanent magnets used in wind turbines, electric vehicles and other applications. We introduce GCMat, a dynamic agent-based model that includes interacting agents at five supply chain stages consisting of mining, metal refining, magnet production, final product production and demand. Agents throughout the supply chain make pricing, production and inventory management decisions. Deposit developers choose which deposits to develop based on market conditions and detailed data on 57 rare earth deposits. Wind turbine and electric vehicle producers choose from a set of possible production technologies that require different amounts of rare earths. We ran the model under a baseline scenario and four alternative scenarios with different demand and production technology inputs. Model results from 2010-2013 fit well with historical data. Projections through 2025 show a number of possible future price, demand, and supply trajectories. For each scenario, we highlight reasons for turning points in market conditions, for differences between $\mathrm{Nd}$ and Dy markets, and for differences between scenarios. Because GCMat can model causal dynamics and provide fine-grain representation of agents and their decisions, it provides explanations for turning points in market conditions that are not otherwise available from other modeling approaches. Our baseline projections show very different behaviors for $\mathrm{Nd}$ and Dy prices. $\mathrm{Nd}$ prices continue to drop and remain low even at the end of our simulation period as new capacity comes online and leads to a market in which production capacity outpaces demand. Dy price movements, on the other hand, change directions several times with several key turning points related to inventory behaviors of particular agents in the supply chain and asymmetric supply and demand trends. Scenario analyses show the impact of stronger demand growth for rare earths, and in particular finds that $\mathrm{Nd}$ price impacts are significantly delayed as compared to Dy. This is explained by the substantial excess production capacity for $\mathrm{Nd}$ in the early simulation years that keeps prices down. Scenarios that explore the impact of reducing the Dy content of magnets show the intricate interdependencies of these two markets as price trends for both rare earths reverse directions - reducing the Dy content of magnets reduces Dy demand, which drives down Dy prices and translates into lower magnet prices. This in turn raises the demand for magnets and therefore the demand for $\mathrm{Nd}$ and eventually drives up the $\mathrm{Nd}$ price.

Keywords:

dysprosium

neodymium 
rare earth

critical material

supply chain

agent-based model

\section{INTRODUCTION}

As part of efforts to position the United States as a leader in clean energy technology production, the U. S. Department of Energy (DOE) issued two Critical Material Strategy reports, which assessed 16 metals on the basis of their importance to clean energy development and their supply risk (DOE, 2010, 2011). DOE identified five critical materials: dysprosium (Dy), neodymium (Nd), yttrium (Y), europium (Eu), and terbium (Tb). These critical materials are five of a set of 17 elements known as rare earths, which consist of the lanthanides in the periodic table plus yttrium and scandium. Rare earths are reasonably abundant in the Earth's crust but are rarely found in high concentrations. Separating them from one another is difficult and requires extensive processing to produce separated oxides. Five rare earth elements are commonly referred to as light (lanthanum cerium, neodymium, praseodymium, and samarium), with the remainder referred to as heavy rare earth elements. Rare earths are used in a wide variety of applications, including polishes, catalysts, lasers, fluorescent lights, capacitors, and powerful permanent magnets (used in electric vehicle motors, wind turbines, and consumer electronics). Rare earths are of particular concern because of their importance to clean energy technologies, as well as the potential for supply disruptions.

To understand the implications of rare earth supply disruptions for clean energy, it is important to understand the dynamics across the supply chain, from rare earth oxide extraction to end use application. In this paper, we focus on the use of $\mathrm{Nd}$ and Dy in permanent magnets used in wind turbines and electric vehicles. $\mathrm{Nd}$ and Dy are two of the critical materials identified by DOE, as measured both by their supply vulnerability and their importance for clean energy (DOE, 2010, 2011). Most Nd and Dy is used in neodymium iron boron ( $\mathrm{NdFeB}$ ) permanent magnets, which are the most powerful class of permanent magnet and have seen a steadily increasing share of the permanent magnet market since they were introduced in the 1980s (Dent, 2012). Nd is one of the core materials of these magnets, making up about $30 \%$ of a magnet's weight, while smaller amounts of Dy are added to allow magnets to perform at higher temperatures.

The NdFeB magnet supply chain consists of multiple steps, including mining and initial processing of rare earths into concentrates, separation into oxides, refining into metals, production of alloys and powders, and production of magnets (Shih et al., 2012). Often, more than one of these steps is done by the same vertically integrated company. There has been a trend toward increasing levels of vertical integration. Some companies, such as Molycorp and Great Western Minerals, have focused on obtaining capabilities at each stage of the mine-to-magnet supply chain.

China is a major player throughout the NdFeB magnet supply chain. In $2011,97 \%$ of the world's rare earth production occurred in China (Morrison and Tang, 2012). This dominance has diminished slightly with the initiation of new production from Mountain Pass mine in the United States and Mount Weld in Australia; the latest estimates from the United States Geological Survey (USGS) are that 89\% of 2013 world production occurred in China (USGS, 2014). However, there is 
still very little production of heavy rare earths such as Dy from outside of China. China has also become the leading player in the production of NdFeB magnets, with an estimated $79 \%$ of market share in 2012 (Benecki, 2013). Most of the remaining production is concentrated in Japan. China has also increased its share of wind turbine production, with four of the top ten wind turbine producers now located in China.

The permanent magnet supply chain provides a rich opportunity to explore interactions among the different markets that are not immediately obvious. Markets for wind turbines and electric vehicles are connected because of their use of rare earth permanent magnets. $\mathrm{Nd}$ and Dy oxide markets are also closely connected because they are produced together in the same mines and used together in permanent magnets. Demand for rare earths is also strongly dependent on technological developments that can make demand highly uncertain and difficult to predict. All these supply and demand interconnections among the different rare earths can generate interesting market dynamics that are not well understood.

Rare earth markets have also been volatile in recent years. Prices for most rare earths increased more than tenfold from 2009 to 2011, followed by a significant drop in prices that continued through 2013. This price spike and associated market disruptions highlighted the need for an improved capability to anticipate and respond to future market developments. It also highlighted the need for an improved understanding of how rare earth market developments impact the development of clean energy technologies, and how clean energy technology developments impact rare earth markets.

The rare earth permanent magnet supply chain presents an opportunity for using systems-level modeling to explore recent and possible future market dynamics and the effect of market conditions. Such modeling is largely absent in the existing literature, although there is a wide body of literature devoted to understanding different aspects of rare earth supply chains. Studies have explored the industrial structure, geographical concentration, and market power in the supply chain (DOE, 2010, 2011; Humphries, 2013; Shih et al., 2012) and analyzed the causes of the recent spikes in rare earth prices (Massari and Ruberti, 2013). Many studies have also projected demand or supply for $\mathrm{Nd}$, Dy, and other rare earths and, in some cases, compared independent demand and supply projections to identify potential gaps between them (Alonso et al., 2012; DOE, 2010, 2011; Hatch, 2011; Hykawy et al., 2010; Kingsnorth, 2013; Shaw and Chegwidden, 2012). While these independent projections provide useful insights, a number of questions remain unanswered:

- How will markets adjust to accommodate any supply shortages that are identified?

- What will the impact on prices be?

- How will technological developments be affected and can they help to alleviate these shortages?

- How will the development of new deposits respond to changing market conditions?

- How do market structures and behaviors throughout the supply chain influence the outcomes?

This paper addresses some of the gaps in the existing literature. We conducted a quantitative, model-based, forward-looking analysis of the key complexities of $\mathrm{Nd}$ and Dy supply chains and 
markets. The analysis was conducted by using the Global Critical Materials (GCMat) model. GCMat is a newly developed, dynamic model of rare earth global supply chains that captures the relevant system complexities and includes the entire value chains - from mining to magnet production to end use applications.

The remainder of the paper is structured as follows: Section 2 documents the GCMat model design, including the structure of the model and key assumptions. Full details regarding the model assumptions are provided in the online supplemental materials. Section 3 describes the inputs used in the baseline scenario and the efforts that were made to calibrate and validate our model. Section 4 presents model results and discusses insights gained from the simulation runs. Here, we demonstrate how the model can contribute to a better understanding of important historical developments and explore market outcomes under alternative future scenarios. Finally, Section 5 offers conclusions and directions for future research.

\section{METHODOLOGY}

\subsection{Background}

Modeling resource and commodity markets has a long history. Approaches include econometric, equation-based models that focus on the short term, with structural relationships derived from historical data (Labys, 1978); partial equilibrium models of commodity and energy markets that include explicit detail on the underlying determinants of supply and demand; and alternative market structures, such as imperfect competition (Takayama and Judge, 1971; Salant, 1982). In other work, Macal and Hill (1985) adopted approaches used for modeling energy markets to model global material markets using a partial equilibrium approach to assess the impacts of increasing adoption of electric vehicles and batteries on nickel and lead prices. Alonso (2010) developed a system dynamics model for the platinum supply chain to examine the effects of material scarcity on manufacturers and found that recycling may stabilize prices in a market characterized by highdemand growth rates and slow supply additions. Andriamasinoro and Angel (2012) propose a multi-agent system model for the industrial mining sector in Burkina Faso.

The present work is a bottom-up analysis of rare earth flows using agent-based modeling, a relatively new approach to modeling complex systems composed of interacting, autonomous "agents" (Macal and North, 2010). Agents have behaviors, often modeled by simple rules, and interactions with other agents, which in turn influence their behaviors. Agent-based modeling offers a way to simulate dynamic economic markets that are composed of agents who (1) have complex decision-making behaviors, (2) interact with and influence each other, possibly indirectly through market signals, (3) learn from their experiences, and (4) adapt their behaviors so they are better suited to sustaining themselves in a dynamic market environment. The Repast Simphony agent-based modeling toolkit provides a framework for implementing and using agent-based models (North et al., 2013) and is the basis for GCMat.

The GCMat model is an agent-based model of the supply chain for critical materials. GCMat was developed with the goal of exploring the interactions among agents in the global $\mathrm{Nd}$ and Dy supply 
chains, including oxide miners; metal refiners; magnet producers; wind turbine, vehicle, and electric bicycle manufacturers; and sources of final demand. This section provides an overview of the structure and key assumptions of the model. Further details are provided in the supplemental materials.

\subsection{Model formulation}

Figure 1 shows the types of agents in the model, how they relate to each other, and some of the key decisions made by each agent type. Mine managers sell oxides to metal refiners, which convert them to metals and sell primarily to magnet producers, with some additional output going to nonmagnet uses. Magnet producers sell their magnets to end use producers, which include wind turbine producers, vehicle producers, and electric bicycle producers, as well as to other sources of magnet demand. End use producers then sell their products to corresponding sources of final demand. Mine managers also manage multiple deposits, with a separate deposit developer agent for each deposit. For simplicity, oxide separation is included in the mining stage, and powder and alloy production is included in the magnet production stage.

The number of boxes shown at each level in Figure 1 represents the number of agents at that level in the model (e.g., $\times 57$ under deposit developers). There are only two mine managers, two metal refiners, and two magnet producers; these represent regional aggregations: one for China and one for the rest of the world (ROW). These aggregations are used due to limited data availability on individual companies. The distinction between China and the rest of the world is the most important to capture due to China's key role in rare earth supply chains. The two aggregate mine managers also manage a total of 57 deposit developers, 9 in China and 48 in the rest of the world, that each control the development of a separate deposit that has been identified as a current or potential future producer. Electric vehicle $(\times 9)$ and wind turbine $(\times 10)$ producer agents represent the top current producers of these products. A single electric bicycle producer is also included. Agents are also included to represent sources of demand for two types of wind turbine, three types of vehicle, and one type of bicycle, as well as for sources of demand for metal and for two types of magnet that are not modeled in more detail. Wind turbines and electric vehicles are modeled in the most detail because of their potential for growth with accelerated development of clean energy technologies, an area of interest for DOE. While not explored in this paper, our treatment of these sectors paves the way for future work examining scenarios with rapid clean energy development in more detail. Agents at each level act independently; the trend toward vertical integration is not currently captured in the model. The bullets under each agent show some of the key decisions made at each level. A comprehensive list is available in the supplemental materials. 


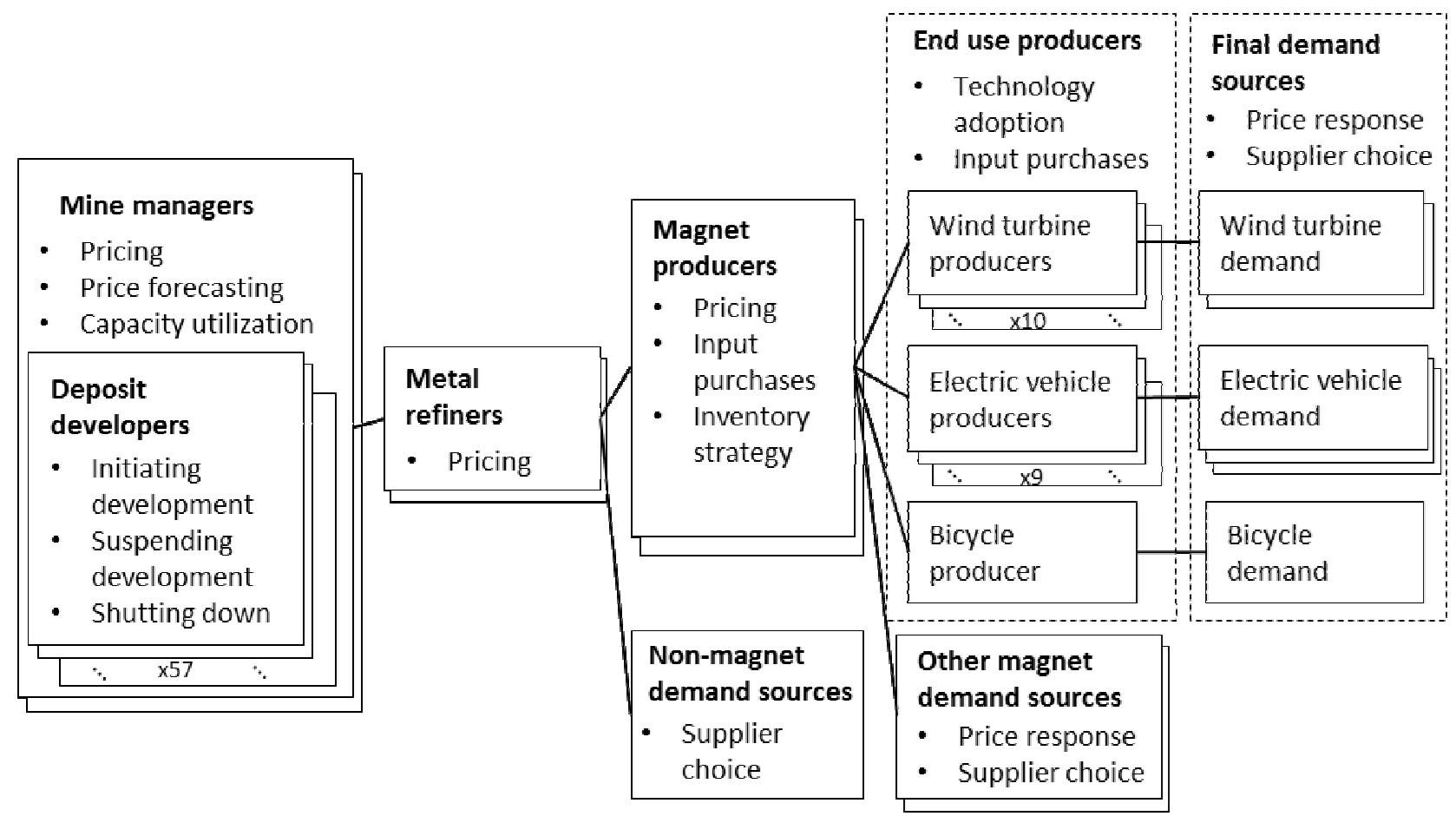

Figure 1. The GCMat model agents and the key decisions made by each agent type.

Model runs are executed in time steps of one week, beginning in January 2010 and ending in January 2025. In each time step, price information is passed up the supply chain from mine managers to final demand sources, after which demand requests are passed back down to mine managers. Each agent then meets these demand requests if they can, and goods are passed back up the supply chain. Each agent also makes additional internal decisions, such as production levels, technology choices, and price forecasts.

Figure 2 shows the data dependencies for a mine manager's decisions in each time period. Details for other agents are provided in the online supplemental materials; we briefly summarize the most important decisions and the factors that influence them in Section 2.3. 


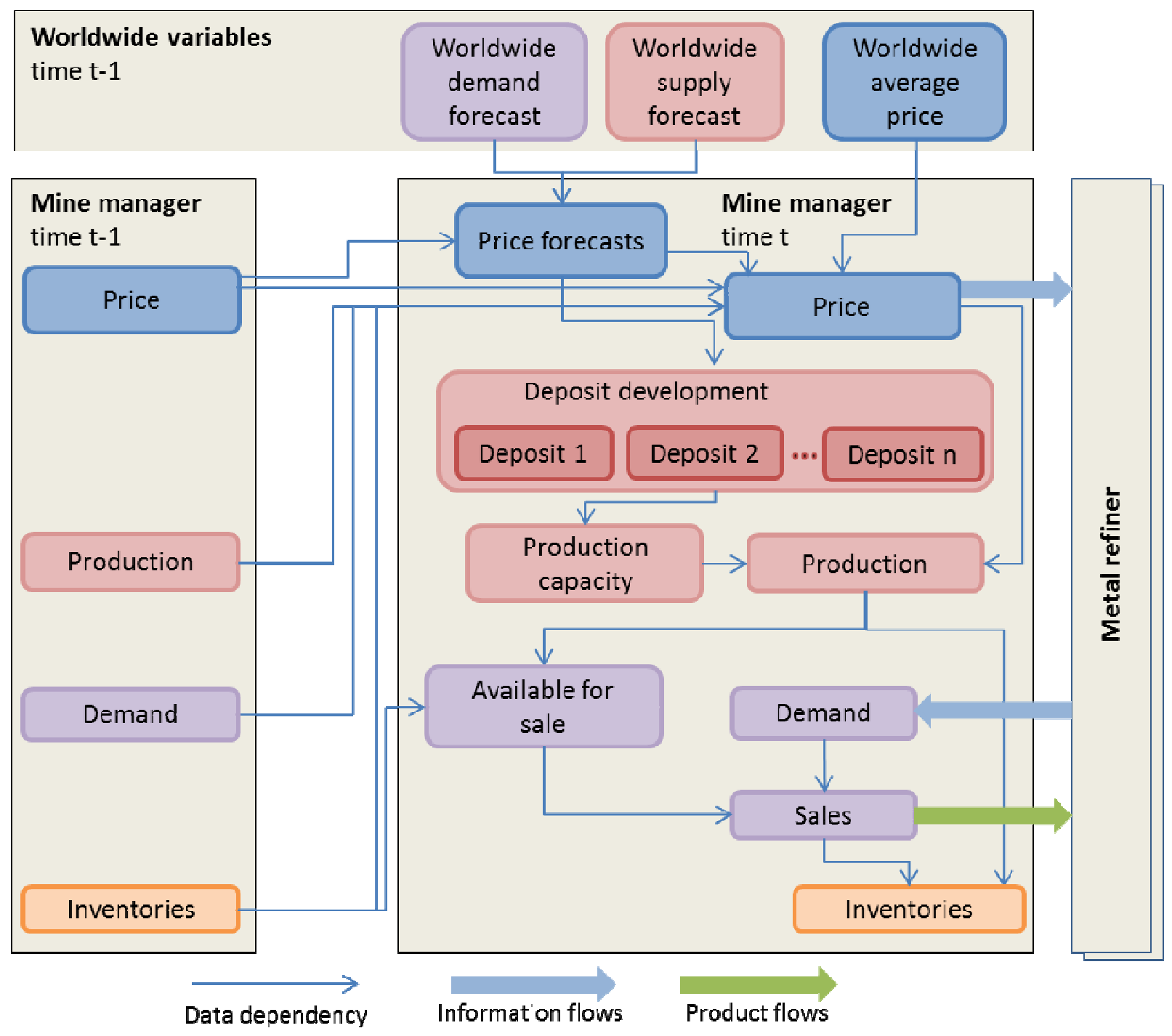

Figure 2. Data dependency diagram for mine manager agent decisions. Each variable is computed by an algorithm in GCMat on the basis of indicated input variables.

\subsection{Key model agent decision rules}

\subsubsection{Price forecasting}

Price forecasts are made by deposit developers in their deposit development decisions and by mine managers in their pricing decisions. Both use the same factors in their price forecasts: their most recent price, a moving average of past prices, and worldwide demand and supply forecasts. Demand forecasts are based on past demand patterns, while supply forecasts are based on the amount of new capacity being developed at different stages of development. If demand and supply stay in balance, prices are expected to gradually return to an exponentially weighted moving average of past prices (with half the weight given to the last 3 years). If demand is forecast to exceed supply, the discrepancy will drive prices higher than that trajectory, and if supply is forecast to exceed demand, prices will remain lower. In the long run, the impact of the supply and demand 
forecasts diminishes, and prices trend toward the moving average. Price forecasts, $P F_{o, t f}$, for a rare earth oxide $o$ other than $\mathrm{Nd}$ and Dy, at future time if are assumed to follow $\mathrm{Nd}$ and Dy prices to varying degrees depending on the price relationships found in the historical data, shown in the equation below and in Table $1 . b_{o, N d}$ and $b_{o, D y}$ are the regression coefficients shown in Table 1. With the exception of Gadolinium and Yttrium, light rare earth prices are more tied to Nd prices, and heavy rare earth prices are more tied to Dy prices.

$$
\ln \left(\frac{P F_{o, t f}}{P F_{o, t f-t}}\right)=b_{o, N d} \times \ln \left(\frac{P F_{N d, t f}}{P F_{N d, t f-t}}\right)+b_{o, D y} \times \ln \left(\frac{P F_{D y, f f}}{P F_{D y, t f-t}}\right)
$$

Table 1. Coefficients for relationship between rare earth oxide prices

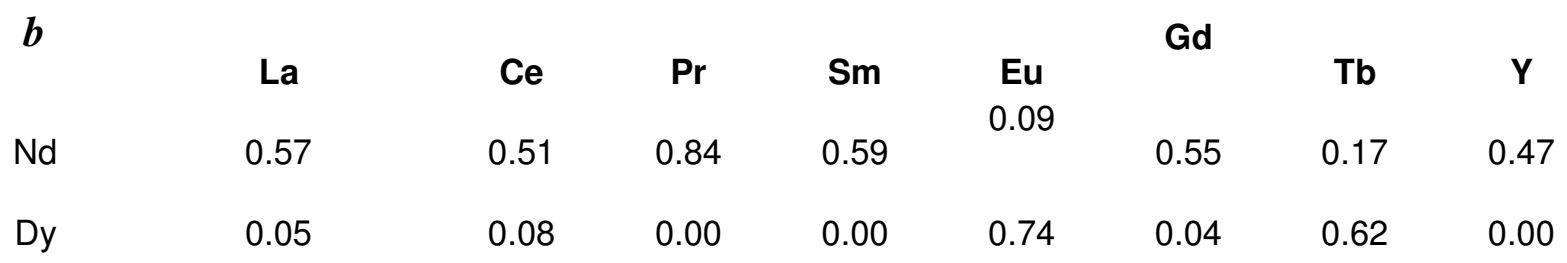

\subsubsection{Deposit development}

Deposit developers control the development of each deposit, making development decisions on the basis of forecasted rare earth prices, the deposit's characteristics (e.g., ore composition), and expected capital and operating costs. It is assumed to take a minimum of 7 years from when a resource has been identified and development of a deposit is initiated to when it begins producing. Figure 3 shows the states that a deposit can be in and the possible transitions between these states. Deposit development decisions are guided by profitability forecasts, which in turn depend on price forecasts. If the expected internal rate of return (IRR) exceeds a threshold (15\%), deposit developers initiate the development process. If the IRR falls below a lower threshold (5\%), development is halted, unless the deposit is in the final 2.5 years of its development, when financing has been lined up and construction is under way. A deposit that is already producing shuts down only if it has accumulated losses for an extended period and developers expect to lose more money in the future. Developers can choose to reopen deposits that have been shut down but such deposits are set back by 2 years in their development stage.

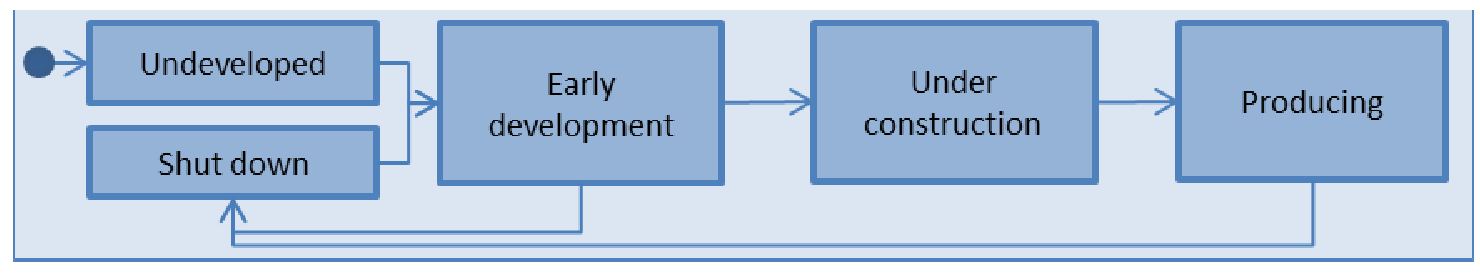

Figure 3. Deposit development state chart.

\subsubsection{Pricing}

Prices of each product throughout the supply chain are set by suppliers. Buyers decide how much to purchase at those prices. Metal refiners and end use producers set prices on the basis of their costs 
of production, with a fixed markup. Mine managers and magnet producers use more complicated pricing rules, with the goals of keeping the demand for their product in balance with their production and keeping their inventories near target levels.

Mine managers and magnet producers increase their prices if the demand for their product exceeds their production or if their inventories are below a target level, which is a fixed portion of expected demand. Mine managers also account for price forecasts in their price-setting decisions. If they forecast that prices will rise, they will raise their current prices. Such increases will decrease the demand for their product, which they accept because it allows them to build their inventories and sell more later, when prices have risen further. Magnet producers also factor in the cost of inputs when setting their prices. Each mining agent and magnet-producing agent sets prices independently, based on their own production and demand, but with an adjustment to move their prices in the direction of the worldwide average price.

\subsubsection{Production}

Metal refiners and end use producers produce just enough to meet demand. Magnet producers increase their production levels when production is more profitable than usual, as measured by the markup they are receiving, and decrease production levels when the markup is low. Mine managers' production is constrained by the capacity of the deposits they have developed. Chinese production is further constrained by government production targets. The rest of the world produces at full capacity if prices are high enough but reduces production below capacity when the moving average of their selling prices drops below a fixed cutoff based on historical prices. The amount that these producers reduce production depends on how far the price drops below this cutoff.

\subsubsection{Input purchases}

Metal refiners, magnet producers, and end use producers purchase enough inputs to meet their desired production levels. Magnet producers also carry input inventories, and they can adjust their input purchases to meet inventory targets. Magnet producers and end use producers also decide what share of their inputs to purchase from each supplier. They adjust these shares gradually if there is a difference between the costs of buying from the different suppliers.

\subsubsection{Technology adoption}

Wind turbine, electric vehicle, and electric bicycle producers choose among several technologies for use in making their products; each of these technologies requires different rare earth content. Wind turbine producers choose between doubly fed induction generator (DFIG) turbines, which require no permanent magnets (PMs); direct-drive turbines, which require large $\mathrm{NdFeB} P M s$; hybrid drive turbines, which require smaller PMs; and turbines that use large PMs but require no Dy. Electric vehicle and bicycle producers choose between standard technologies that use two PM motors, technologies that replace one PM motor with an induction motor, technologies that use only induction motors, and technologies that use two PM motors but with reduced Dy content. These technology options are consistent with those being pursued by top turbine and vehicle companies.

Each producer initiates a new product line each year and chooses which technology to use for the new product line on the basis of the relative production costs using each technology, accounting for 
the costs of rare earths. The relative benefits of each technology are captured only by their costs; there is no difference in product performance based on the technology used. Low-cost technologies are selected with higher probability using a technology selection function from Boyd et al. (1982):

$$
p\left(t_{j}\right)=\frac{\left(\frac{1}{c_{j}}\right)^{\alpha}}{\sum_{i}\left(\frac{1}{c_{i}}\right)^{\alpha}}
$$

where $p\left(t_{j}\right)$ is the probability of selecting technology $t_{j}, c_{j}$ is the production cost using technology $t_{j}$, and $\alpha$ is a parameter that determines the likelihood of choosing the lowest-cost technology.

It then takes 3 years for the product lines to enter the market, which leads to a delayed impact of the technology choice on rare earth demand. Because of this, the rate of use of rare earths in electric vehicles and wind turbines responds to rare earth prices, but much of the response comes 3 years or more after the initial price signal. There can be a more immediate response as well if multiple technologies are already being used, because the existing technologies that can produce at a lower cost will see their production shares increase, while the production shares of more expensive technologies decrease.

\subsubsection{Inventory management}

Inventories are held at three points in the supply chain: mine managers hold inventories of the rare earth oxides that they produce but have not yet sold; magnet producers hold inventories of the rare earth metals that they purchase as inputs; and magnet producers hold inventories of the magnets that they produce but have not yet sold. Product inventories, both at the mine and magnet producer levels, are updated simply by adding new production and subtracting new sales from previous levels. Both agents have target levels for these inventories, which are a fixed portion of their expected demand. They cannot control their inventories directly because they do not have control over how much of their product is purchased. Instead, they manage their inventories by adjusting their prices. If inventory levels fall below the target levels, they will raise their prices, which will lead to a drop in the demand, which in turn will help to raise inventories closer to the target level. The reverse occurs if inventory levels are higher than targets.

Magnet makers also have target levels for their input (rare earth metal) inventories. They can control these inventories more directly than their product inventories because they can control how much of these inputs they buy, as long as there are sufficient supplies available. As a result, input inventories are normally at their target levels. Target input inventory levels depend on expected production levels and on exogenous model inputs that specify the number of months of production that magnet makers would like to be able to satisfy, which can vary over time. The exogenous inputs used in our baseline scenario are described in Section 3.

\subsubsection{Demand response to prices}


The demand for wind turbines, electric vehicles, electric bicycles, and other products using magnets respond to the prices of those products, using a constant price elasticity of demand. The price elasticity used for wind turbines, electric vehicles, and bicycles is -1 based on vehicle demand elasticity estimates. This value translates into much lower demand elasticities for $\mathrm{Nd}$ and Dy because they make up a small portion of the final product price. Other uses of magnets, besides wind turbines and vehicles, are divided into high-Dy and low-Dy magnet applications. High-Dy magnets are given a higher price elasticity of demand (-0.8) than low-Dy magnets $(-0.2)$ because the possibility of reducing the Dy content in magnets makes Dy demand somewhat more price responsive than $\mathrm{Nd}$. These other magnet demand elasticities account for both final product demand response and shifts in production technologies because production technologies are not modeled directly, as they are for wind turbines and vehicles.

\subsubsection{Government agents}

The only role for government agents in the current model is that the Chinese government can set exogenously determined production targets, which constrain total Chinese production. Other government influences, such as export controls and taxes, stockpiling strategies, setting environmental rules and permitting processes, and enforcement efforts could be added in future work. They could be included either as exogenously specified scenarios, or as endogenously modeled government agents who respond to market conditions when setting their policies.

\section{BASELINE SCENARIO ASSUMPTIONS AND SETUP}

\subsection{Assumptions}

In the baseline scenario, the inputs are drawn from a variety of sources, which are described in detail in the supplemental materials.

Demand projections for final products are determined endogenously by the model, but they use as input a set of business as usual (BAU) demand trajectories that follow those in DOE's Critical Materials Strategy (DOE, 2011). The BAU trajectories determine how final product demand would evolve if prices remained constant. Demand responses to changing prices are applied on top of changes in BAU demand. The baseline BAU demand trajectories for wind turbines and electric vehicles follow the low-deployment scenario in DOE (2011), which is based on BAU assumptions about clean technology development. Demand levels for 2010-2012 are updated to reflect the latest data from the International Energy Agency (IEA) (2013) and the Global Wind Energy Council (GWEC) $(2011,2012,2013)$. Non-clean-energy BAU demand growth matches projected gross domestic product (GDP) growth rates of 3.6\% per year through 2020, and 2.9\% afterwards.

Model inputs relating to technologies used and cost trajectories over time were chosen to be consistent with market trends we observed through consultation with DOE experts. Most hybrid vehicles currently have electric motors with two NdFeB permanent magnets. However, following the recent market disruptions, a number of key hybrid vehicle producers announced plans to reduce the rare earth content of their motors, either by replacing one of the motors with an induction motor that does not use rare earths, or by reducing the Dy content of the magnets they 
use. Most wind turbines currently use DFIGs, which do not require NdFeB permanent magnets. However, direct-drive and hybrid-drive turbines using NdFeB magnets have gained some market share recently. Direct-drive turbines require less maintenance and are more scalable than DFIG turbines, making them attractive for large turbines and, especially, offshore turbines. Hybrid-drive turbines have some of the advantages of direct-drive turbines, but they use a smaller magnet. Consultation with industry experts has indicated that the recent rare earth market disruptions may limit the adoption of direct-drive turbines for onshore wind farms, while hybrid-drive turbines are more likely to continue gaining market share. New technologies that would allow Dy-free permanent magnets to be used also have the potential to gain market share down the road.

The magnet sizes and rare earth contents required to produce final products using each technology were taken from DOE (2011). Direct-drive wind turbines are assumed to use $600 \mathrm{~kg}$ of magnet per megawatt (MW), while hybrid-drive turbines use $200 \mathrm{~kg}$ of magnet per MW. Hybrid and electric vehicles are assumed to use $1 \mathrm{~kg}$ of magnet per motor, for a total of $2 \mathrm{~kg}$ per vehicle using standard technology. The Nd content of all magnets is assumed to be $31 \%$. The Dy content of magnets used in vehicles can be either $6 \%$ or $2 \%$, depending on the technology used. For wind turbines, the Dy content can be either $4 \%$ or $0 \%$.

Figure 4 shows BAU demand trajectories for $\mathrm{Nd}$ and Dy oxide that are generated by combining the BAU final demand trajectories with the technology inputs described above, assuming no change in the mix of technologies used over time. In the absence of other market developments, demand for $\mathrm{Nd}$ and Dy oxides would grow at average annual rates of $3.2 \%$ and 3.8\%, respectively, through 2025. These trajectories include only $\mathrm{Nd}$ and Dy demand that is driven by final product purchases - demand that goes to building inventories is not included. 

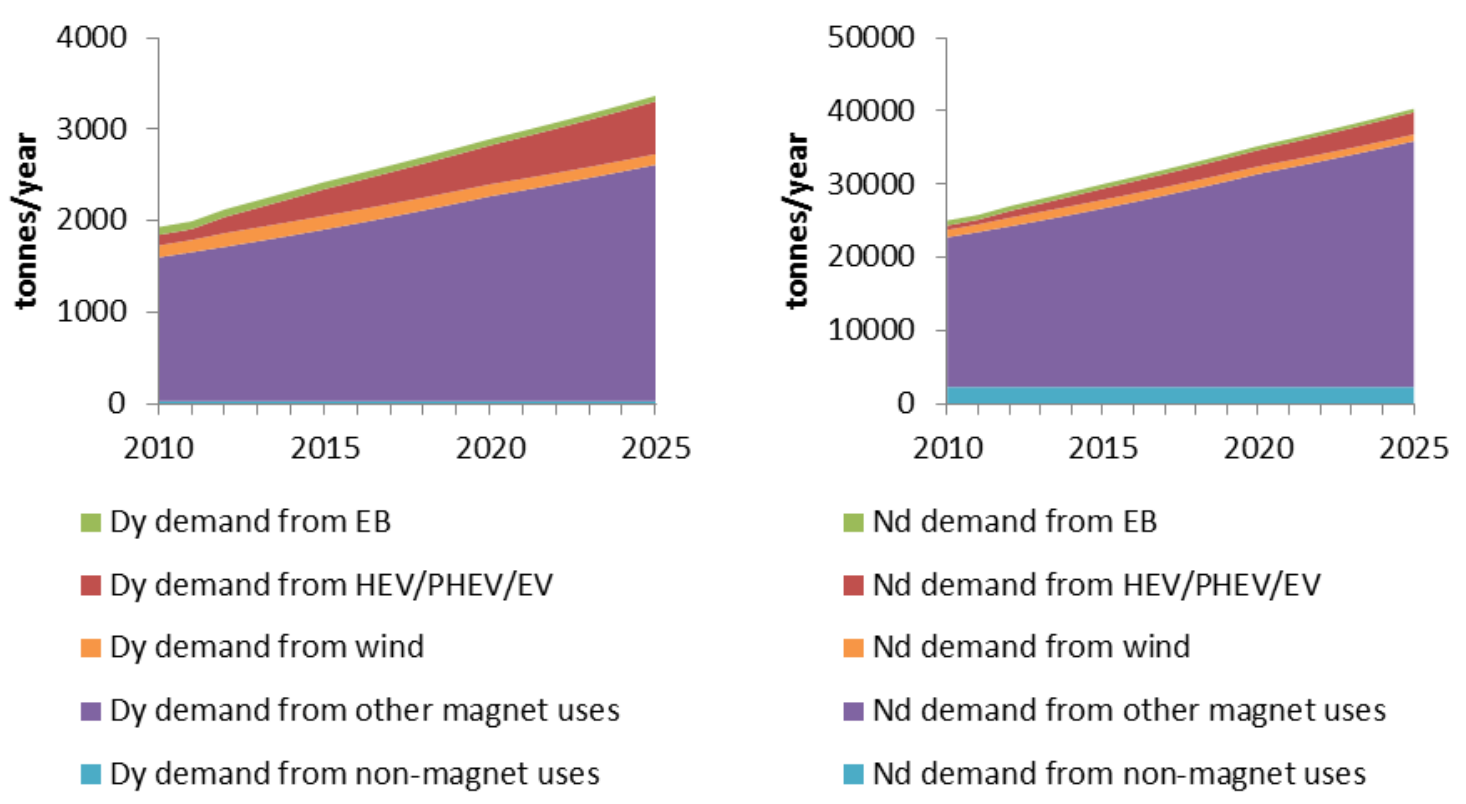

Figure 4. BAU demand trajectories, baseline scenario. (Sources: DOE [2011], with updated data from IEA [2013] and GWEC [2011, 2012, 2013]) (Notes: EB = electric bicycles, HEV = hybrid electric vehicle, $\mathrm{PHEV}=$ plug-in hybrid electric vehicle, and $\mathrm{EV}=$ all-electric vehicles)

Rare earth oxide production numbers through 2012 are based primarily on data from the USGS $(2013,2014)$, supplemented by estimates of Russian and Brazilian production (Hatch, 2011) and an estimate of the amount of illegal Chinese production (DOE, 2010). For each currently producing deposit, as well as new deposits with potential for future production, data inputs to the model include the mix of rare earths in the deposit, expected capital and operating costs, expected production capacity, and the earliest possible start date for production. These data are taken primarily from the Technology Metals Research (TMR) Rare-Earth Index and other TMR data (TMR, 2012; Hatch, 2011; Hatch and Lifton, 2012), DOE's critical materials strategy (DOE, 2011), and information from technical reports prepared by the deposit owners (see supplemental materials for a full review). When cost estimates are unavailable, we estimate costs based on production capacity and the grade of the deposits, using a relationship generated from those deposits for which data are available.

Future Chinese production limits are assumed to remain at 2012 levels. Future Chinese supply is highly uncertain, but a flat trajectory over time is plausible given Chinese efforts to limit rare earth extraction due to environmental and resource conservation concerns (Wübbeke, 2013) and matches the low Chinese supply scenario from Hatch (2011). Alternative scenarios for Chinese production can be explored with this model, but we leave this for future work. Data on ore composition, planned production capacity, and the earliest possible start date for each deposit, along with Chinese supply assumptions, together determine a trajectory for the maximum possible production the model could generate. This trajectory is shown in Figure 5, and is compared with our estimates of BAU demand from Figure 4. Production capacity for Nd oxide rises sooner than for 
Dy oxide because the most advanced projects, particularly those at the Mountain Pass and Mount Weld mines, contain primarily light rare earths.
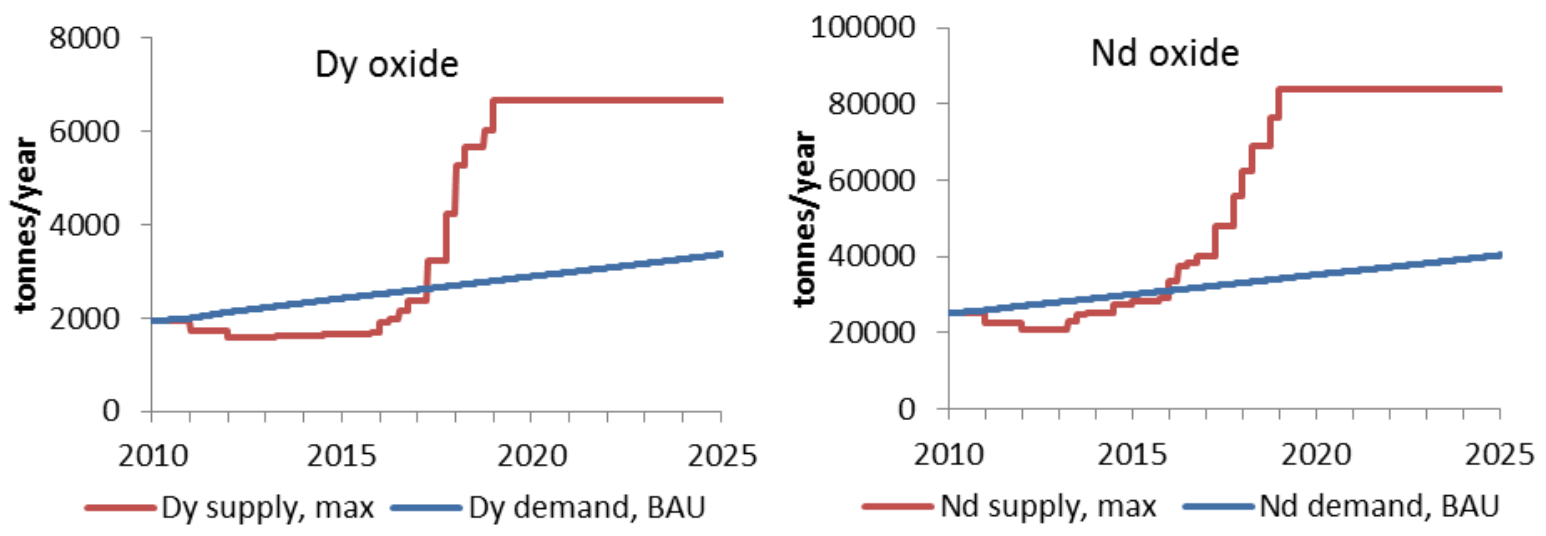

Figure 5. Maximum possible Nd and Dy oxide supply versus projected BAU demand, baseline scenario. (See text for sources.)

Magnet producer target inventories of $\mathrm{Nd}$ and Dy are also specified as an exogenous input to the model. In the baseline scenario, target inventories are built up from February 2011 to July 2011 and drawn down from August 2011 through June 2013. Inventory targets increase from 6 to 9 months of expected production during the build and then return to 6 months by the end of the drawdown, where they remain for the remainder of the model run. The timing and size of the inventory build and subsequent drawdown are chosen to calibrate model prices to historical data. Prices used are Chinese freight-on-board (FOB) prices from Metal-Pages (2013), which capture the prices of Chinese exports to other countries.

Additional parameters and inputs that determine agent behaviors such as response elasticities, inventory targets, forecasting rules, and deposit development criteria are detailed in the supplemental materials.

\subsection{Model setup}

We generate results for 30 model runs and produce averages and ranges for the results. The variation between model runs captures only one source of uncertainty: the choice of technology used to produce wind turbines, vehicles, and bicycles. We find that 30 runs are sufficient because the averages and standard deviations of the results do not change much with additional model runs.

The model generates output showing time trajectories for the prices, production levels, sales, and inventories for Dy and Nd oxides and metals, ten types of magnets, two types of wind turbines, three types of electric vehicles, and electric bicycles. It displays worldwide averages and totals, as well as breakdowns by region, deposit, or company. The model also displays results such as price forecasts and technology shares that help to highlight the operations of key modules.

We devoted significant effort to calibrating the model to historical data so that, under a reasonable set of inputs, the GCMat model results match historical price, supply, and demand data for 2010 to 
mid-2013. The baseline results track historical price patterns very closely and are consistent with estimates of supply and demand levels that are available from other sources. The model's design, assumptions, and results underwent an external peer review by a number of industry stakeholders, including a rare earth company, a magnet producer, and a wind turbine producer, as well as a government agency and a research institute.

\section{RESULTS}

In this section, we provide results for the baseline scenario, as well as several alternative scenarios. The baseline results illustrate that our calibrated model replicates historical patterns from 20102013 and generates projections of future developments from 2013-2025 that rare earth market experts have found to be plausible. We also present two sets of alternative scenarios: one that evaluates the impact of increasing demand growth over time and one that evaluates the impact of technology developments on reducing the Dy content of magnets. These scenarios explore the interdependencies between $\mathrm{Nd}$ and Dy markets.

\subsection{Baseline scenario}

\subsubsection{Nd/Dy oxide demand}

The demand for $\mathrm{Nd}$ and Dy oxides is driven by (1) the demand for final products that use these materials, (2) the choice of technologies used in the final products, and (3) purchases made to build up inventories. This section focuses on (1) and (2), which determine the quantity of rare earths needed to meet final product demand. Both of these drivers of $\mathrm{Nd} / \mathrm{Dy}$ oxide demand respond to prices. Purchases for inventories are discussed in section 4.1.4.

Figure 6 shows two examples of the technology developments over time predicted by our baseline scenario model runs. The results during the historical period are consistent with the technological trends that have been observed in the wind turbine and vehicle industries. The technology forecasts for annual wind turbine installations and new vehicle manufacturing shown in Figure 6 are consistent with the DOE low deployment scenario. Hybrid-drive turbines gain market share at the expense of both DFIG and PM direct-drive turbines, while Dy-free turbines begin to appear after 2020. Two new vehicle drive technologies, one reducing the number of PM motors and the other reducing the Dy content of the magnets, gain market share compared with standard two-PM hybrid vehicle motors.

These technology changes have important impacts on Nd and Dy demand. The penetration of onePM-motor and reduced-Dy-content technologies in electric vehicles leads to a small reduction in $\mathrm{Nd}$ demand and a larger reduction in Dy demand from electric vehicles between 2014 and 2020. The impact of new technologies for wind turbines is a bit more complicated, as hybrid-drive turbines replace both the more-rare-earth-intensive direct-drive turbines and the less-rare-earth-intensive DFIG turbines. At first, these effects roughly offset each other, but after 2015, it is primarily the DFIG turbines that are being replaced, leading to an increase in $\mathrm{Nd}$ and Dy demand per wind turbine. 
Onshore wind turbines

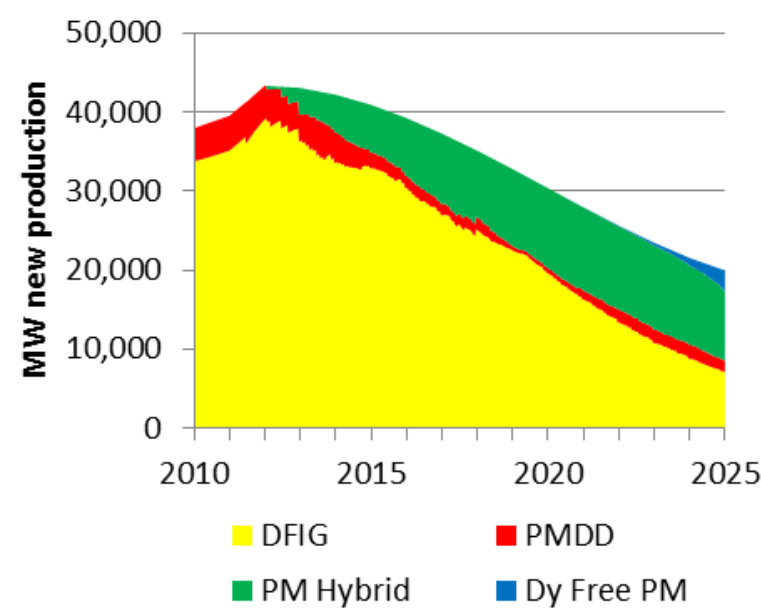

Hybrid-electric vehicles

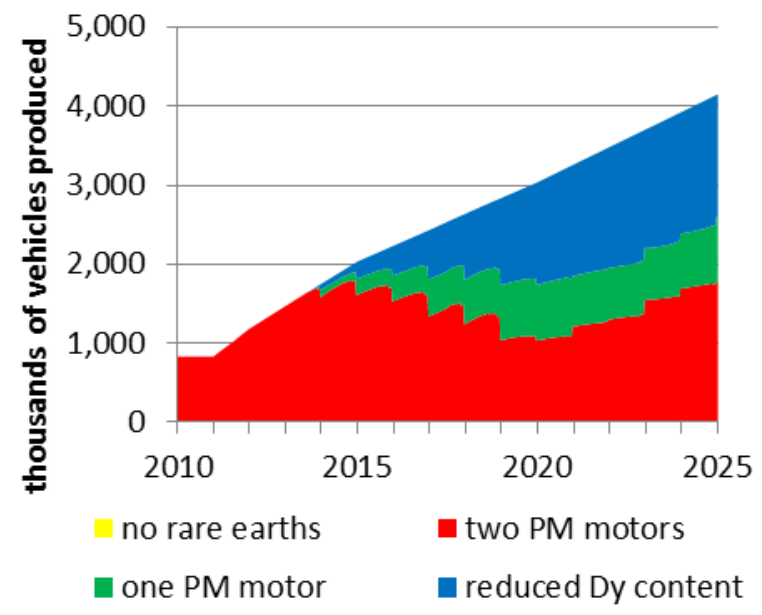

Figure 6. Production of onshore wind turbines and hybrid electric vehicles using different technologies: average baseline scenario projections. (Notes: DFIG = doubly-fed induction generator, $\mathrm{PMDD}=$ permanent magnet direct drive, $\mathrm{PM}=$ permanent magnet $)$

Figure 7 shows the model projections for $\mathrm{Nd}$ and Dy oxide demand, along with BAU demand trajectories and average magnet prices. Demand projections include only demand that is driven by final product demand; purchases used to build inventories are not included. The full range of demand outputs over 30 model runs is shown by the shaded band; the line in the middle of the band represents the median. While most of the model is deterministic, the choice of technology used in vehicle and wind turbine production is a random function, which leads to variation between model runs. There is relatively little variation, which reflects partly the limited amount of random variation that is modeled and partly the market adjustments that keep total market demand in line with supply, even as the technology choices that influence demand are shifting.

Demand for both $\mathrm{Nd}$ and Dy oxide is found to drop initially, but then recover and grow gradually through 2025. Average demand growth over the course of the model run is $2.5 \%$ for $\mathrm{Nd}$ and $2.1 \%$ for Dy. Modeled demand is lower than the BAU demand trajectories shown by the blue dotted line, due to the price responsiveness of demand and to technology trends. The technology trends in electric vehicle drives have the greatest impact on reducing demand for $\mathrm{Nd}$ and especially for Dy, as magnets with low Dy content gain market share in vehicles.

While technology developments are important for the long-term demand trends, the ups and downs in demand over the course of the model run are driven largely by the demand response to magnet prices. Magnet prices are discussed in more detail in Section 4.1.3, but for convenience, we include them here as well, to demonstrate the inverse relationship between magnet prices and $\mathrm{Nd} /$ Dy oxide demand. 

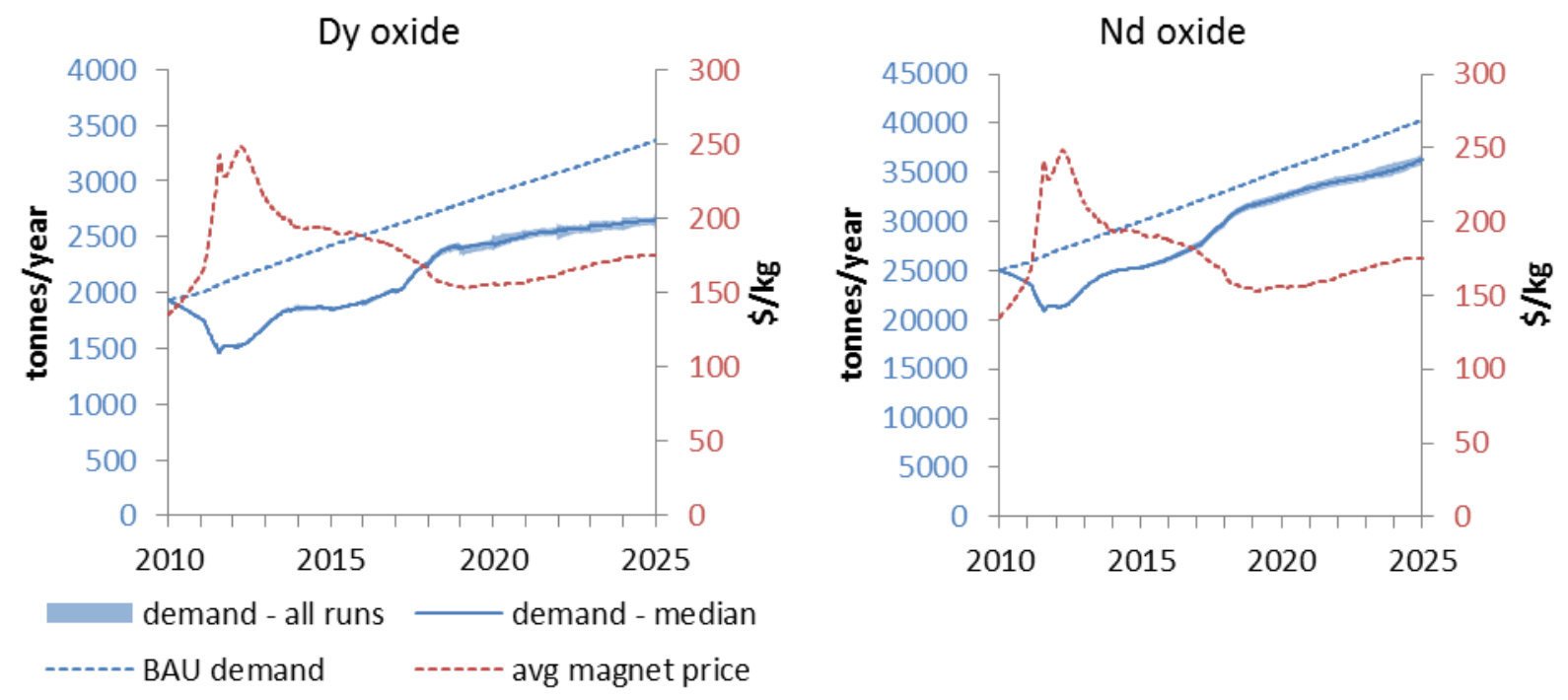

Figure 7. $\mathrm{Nd}$ and Dy oxide demand projections from 30 baseline scenario runs. Also shown are BAU demands and average magnet prices.

While there are few reliable, publically available demand data, a respected source for estimates of this type is Dudley Kingsnorth of Industrial Minerals Company of Australia (IMCOA). Kingsnorth's estimates and forecasts for total rare earth oxide (REO) demand are superimposed on our $\mathrm{Nd}$ and Dy demand forecasts in Figure 8 (Kingsnorth, 2013). His estimates for 2010-2012 and his forecasts for 2013-2014 are close to our model predictions. After 2014, our forecasts diverge somewhat as we project slower growth in 2015 and 2016 than does Kingsnorth. Our slower growth projections reflect relatively conservative assumptions about baseline demand growth. The potential for faster demand growth is explored in alternative scenarios. 


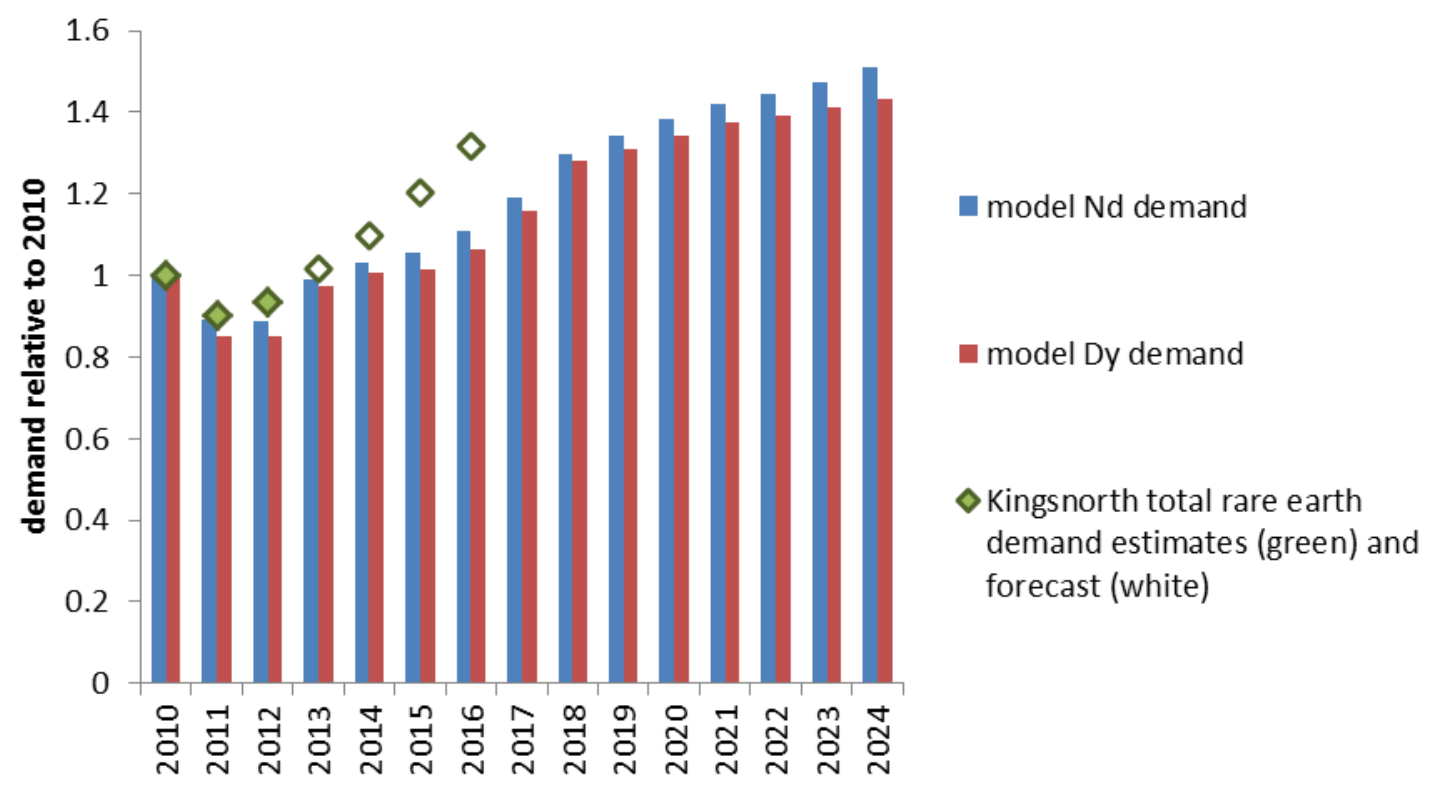

Figure 8. Normalized demand for $\mathrm{Nd}$ and Dy oxides: comparison of average model baseline scenario projections with demand estimates for total rare earths from Kingsnorth (2013).

\subsubsection{Nd/Dy oxide supply}

Figure 9 shows the model's projected supply, broken down between China and the rest of the world. Supply from China drops by 18\% from 2010 to early 2012, following USGS estimates. From there, worldwide supply is projected to increase 74\% (to 2,760 tonnes/year) for Dy and 89\% (to 39,200 tonnes/year) for $\mathrm{Nd}$; all of the increase in supplies will come from outside of China. Chinese supply remains constant due to assumed Chinese production targets in the baseline scenario, as described in section 3.1, which represent one possible scenario for future Chinese production. Nd supplies begin to increase sooner than Dy supplies as a result of the development of deposits with predominantly light rare earths. Nd production is held back from 2015 through 2020 even as more capacity is brought online, as low prices lead suppliers to produce at less than their full capacity rather than cutting prices further. 

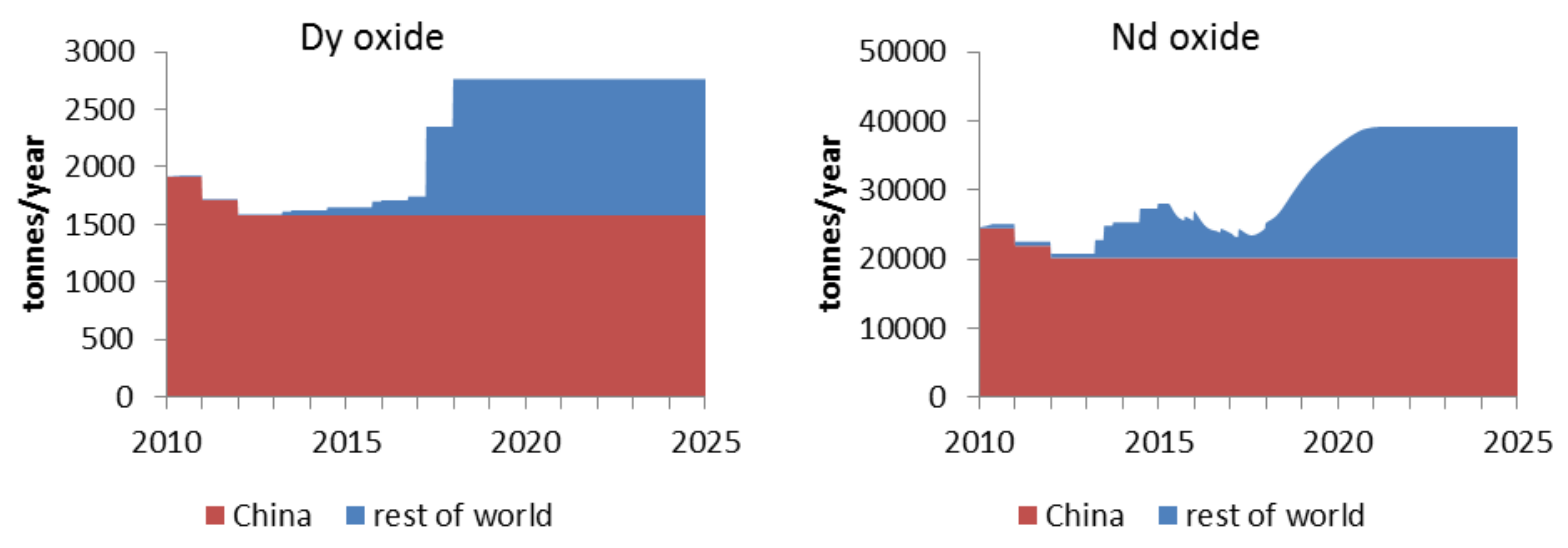

Figure 9. Production of $\mathrm{Nd}$ and Dy oxide in China and the rest of the world: average baseline scenario projections.

These supply developments are endogenously determined in the model on the basis of market conditions. The increase in supply is driven by the development of new deposits, which depends on price forecasts being high enough to justify development. Price forecasts are more stable over time than prices, but they still respond to the same market developments that influence prices. As a result, price forecasts tend to be higher at times when prices are high than they are when prices are low. Figure 10 shows projected $\mathrm{Nd}$ and Dy production capacity, along with the additional production capacity that is actively being developed. The model shows a surge in new projects from 2010 through 2012, because high price forecasts during this period make development of many deposits look profitable. By 2013, when prices have fallen substantially, a number of projects that no longer look profitable have been abandoned. Only the most advanced or the most promising projects survive and continue being developed until they eventually begin producing. For a brief period, no projects are under development, because the projects that survived the falling prices of 2012 and 2013 have all reached production, and future price forecasts remain low enough to hold back the initiation of new projects. Finally, starting in 2019, price forecasts increase again as demand is forecast to surpass production capacity, with no new projects under development to help meet this demand. As a result, active development resumes for a number of projects, although none are completed in 2025. 

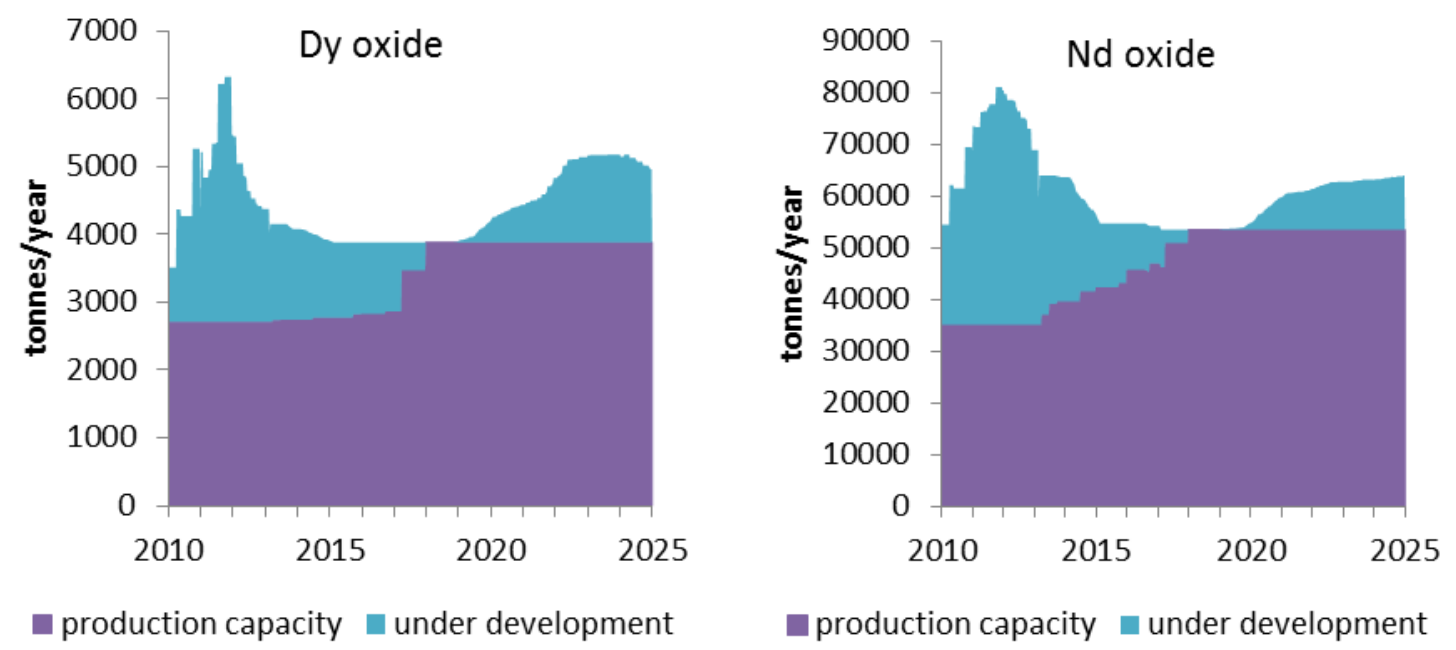

Figure 10. Nd and Dy oxide production capacity and capacity under development: average baseline scenario projections.

Table 2 lists the names of these deposits, along with the dates the model initiates production and their Nd and Dy oxide production levels. The model does not perfectly replicate the development paths that have been observed for each deposit during the historical period; for example, the model predictions for development of phase II of Mount Weld and Mountain Pass mines are not consistent with Lynas' and Molycorp's current plans. The goal of the model is not to predict exactly which deposits will be developed, but to get an idea of how much new production of $\mathrm{Nd}$ and Dy is likely to come online, and how this will respond to market developments. The general trends in real-world investor interest in developing new rare earth deposits have been similar to those seen in the model results, with increasing investor interest in 2010 and 2011, and then falling interest in subsequent years. The number of new deposits that eventually reach production, and the distribution between light and heavy rare earth producers, are also consistent with what other analysts have predicted (Adamas Intelligence, 2013, as reviewed by Hatch, 2013; Merriman, 2013). However, these projections are only one possible scenario. The number of deposits that get developed and when they come online will depend on market conditions, and may not match this schedule. 
Table 2. Deposits that reach production: baseline scenario model projections.

\section{Deposit name}

Mount Weld, phase I phase II

Mountain Pass, phase I phase II

Orissa

Dong Pao

Steenkampskraal

Bear Lodge

Strange Lake

Zandkopsdrift

Mount Weld, Duncan

Norra Karr

\section{First year producing}

2013

2014

2013

2016

2013

2015

2015

2016

2017

2017

2018

2018

\section{Nd oxide \\ capacity \\ (tonnes/year)}

1,994

3,988

2,063

4,577

460

747

863

1,694

1,518

3,176

1,830

754

\section{Dy oxide \\ capacity \\ (tonnes/year)}

28

56

9

19

0

0

48

35

450

156

130

283

\subsubsection{Prices}

Figure 11 shows model projections for $\mathrm{Nd}$ and Dy oxide prices in the baseline scenario. Model prices from 2010 through mid-2013 follow historical prices very closely. The factors behind these historical price movements are dicussed in more detail in section 4.1.4. After 2013, our baseline projections show different behaviors for $\mathrm{Nd}$ and Dy prices. Nd prices continue dropping, as new capacity from Mountain Pass and Mount Weld comes online. This new supply, along with additional capacity that is added from several other light rare earth deposits over the next few years, leads to a market with higher $\mathrm{Nd}$ production capacity than demand for most of the remaining model run. By 2025, demand has nearly caught up to production capacity, but not enough to drive prices up very far.

Dy prices, on the other hand, reverse their downward trend and turn up sharply in 2013. This turnaround comes because of a combination of rising demand in response to the falling prices, and a lack of new supply. New sources of Dy finally become available in late 2017, leading to a rapid reduction in Dy prices. A more modest reduction in Dy prices begins several years before the new supply becomes available, as producers anticipate the new supply and begin lowering prices to try to sell off their inventories before prices fall too far. Beginning in 2019, prices slowly rebound, as demand increases until it is close to capacity, while mine inventories remain below long-run averages. This late resurgence in prices could not have been predicted by looking at demand and supply potential independently, as in Figure 5, which shows potential supply greatly exceeding demand. The resurgence is caused by the cycling of deposit development activity: there is high development activity early on, which eventually leads to sufficient new supply to keep price forecasts low and discourage new development. This lack of new development keeps production capacity levels low enough that demand is able to catch up to supply, driving prices back up. Development activity resumes as demand approaches the new capacity levels, but not fast enough to keep prices from rising before additional supply becomes available. 

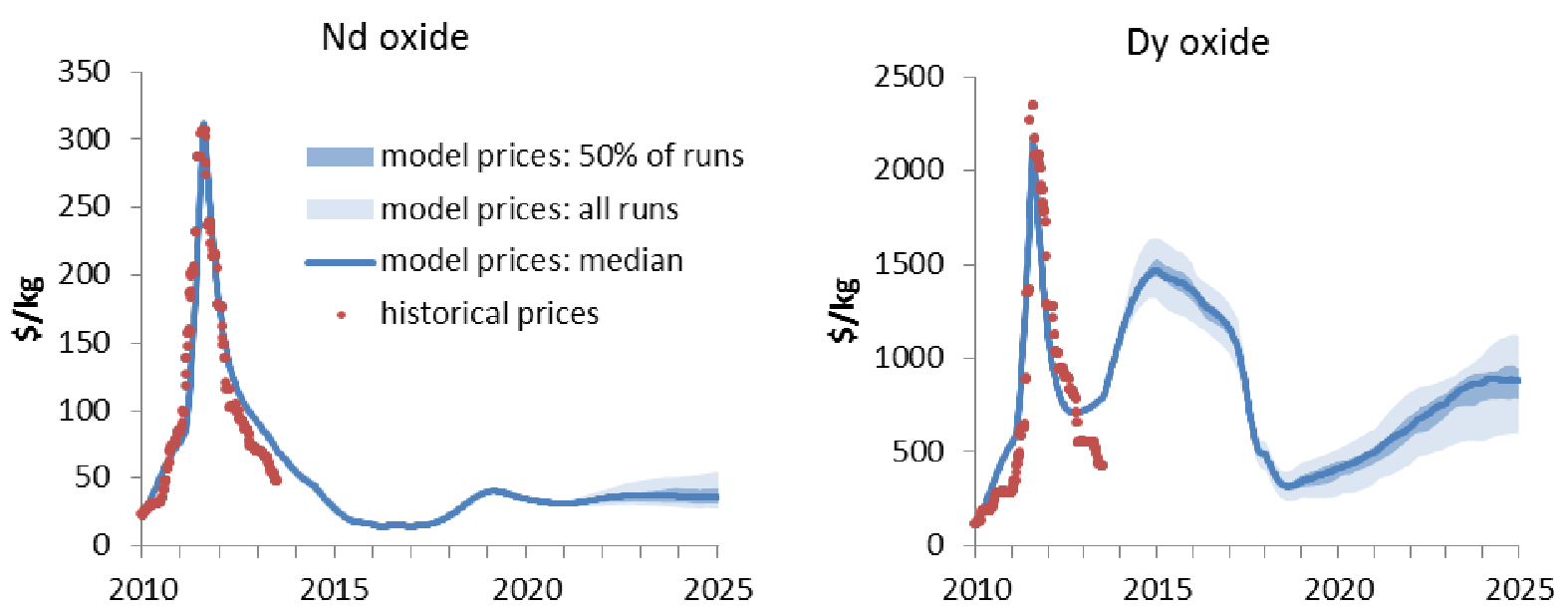

Figure 11. Nd and Dy oxide prices: comparison of model projections from 30 baseline scenario runs with historical prices from Metal-Pages (2013).

Price projections for products further along the supply chain are derived largely from these Nd and Dy oxide prices, but with muted effects, because they make up only a portion of the total product cost. Figure 12 shows how the prices of two different types of magnets, along with the portion of the magnet costs that come from $\mathrm{Nd}$ and Dy purchases, move over time. The two types of magnets differ in terms of the amount of Dy that is used: 3.9\% of magnet weight for the high-Dy magnets and $0.9 \%$ for the low-Dy magnets. Magnet prices largely follow $\mathrm{Nd}$ and Dy prices, but they show some additional movements driven by magnet producer pricing decisions. Most notably, magnet prices rise a second time following the initial spike in rare earth prices, as magnet producers initially try to absorb some of the rising rare earth cost by decreasing profit margins but then return to normal profit margins as rare earth prices start to fall.

Wind turbine and vehicle prices also adjust in response to changes in the cost of magnet purchases. However, the variation caused by rare earth price movements is barely noticeable, because magnets make up a small portion of the total cost of the turbine or vehicle. 

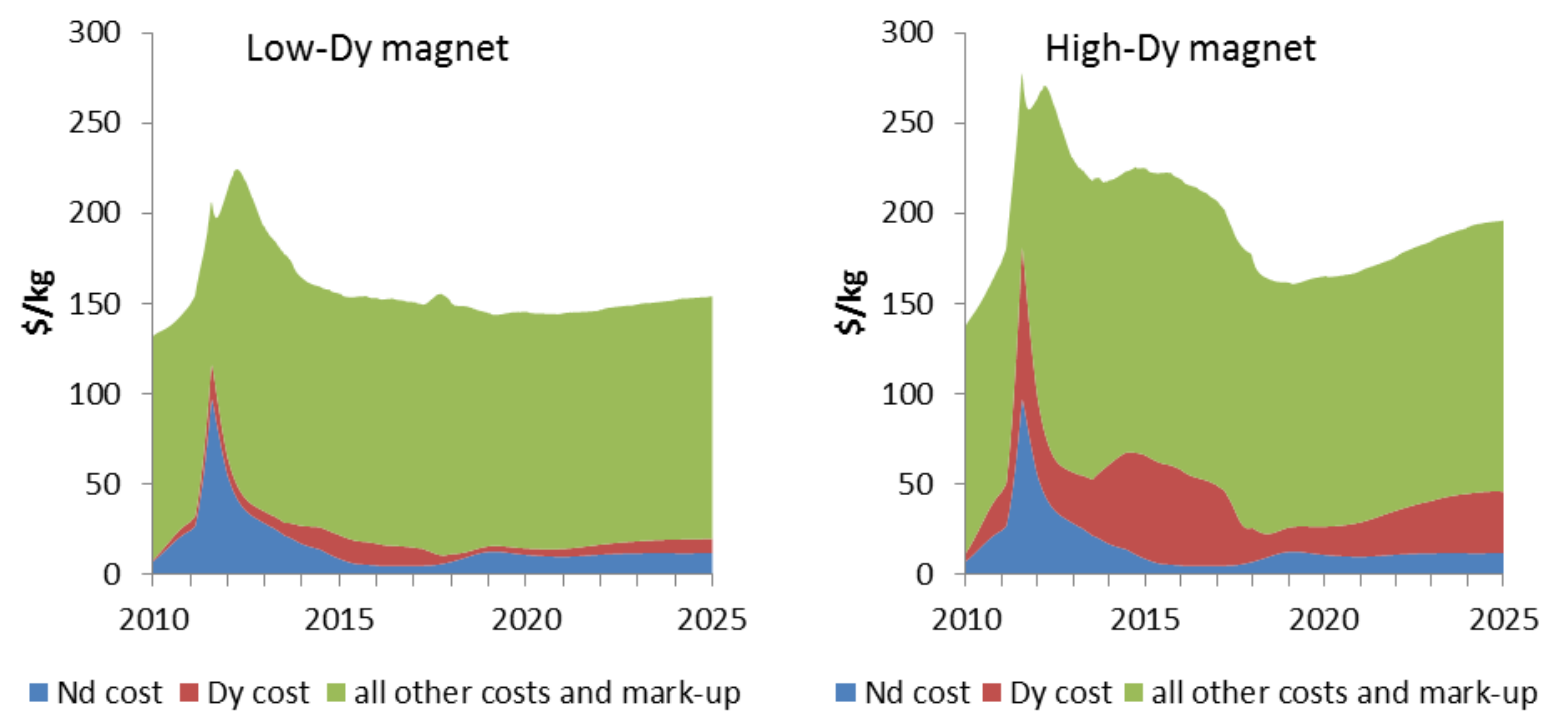

Figure 12. Low- and high-Dy magnet prices: average baseline scenario projections.

\subsubsection{Explaining historical price patterns}

During the period from 2010-2013, prices for Nd and Dy oxides rose dramatically, peaked in 2011, and then fell rapidly through 2013. Our model replicates these patterns well. The price movements in our model are driven by a combination of factors. The initial rise in prices is fed partly by expected growth in demand for products that use $\mathrm{Nd}$ and Dy oxides, while Chinese supply drops and there are few new deposits outside of China that are sufficiently advanced to provide much relief. By the time prices peak in 2011, the demand for rare earths in final products has dropped significantly in response to the high prices, and deposit development activity has increased substantially, with new sources of supply such as Mount Weld and Mountain Pass coming closer to production. These factors contribute to the downturn in prices in 2012.

However, the rapid rise in observed prices from January through July 2011 and the drop in prices from August 2011 through mid-2013 cannot be explained by these factors alone. An important factor driving the rapid increase in price in the first half of 2011 was a rise in rare earth purchases as downstream users of rare earths sought to build their input inventories. The reasons for this inventory build likely centered on concern about the reliability of supplies, as users from outside of China were concerned about Chinese export restrictions and attempted to accumulate inventories while they could, providing a cushion in case of further disruptions. Japanese companies faced additional concerns caused by the temporary cutoff of rare earth shipments from China in late 2010 following the collision of a Chinese fishing boat and two Japanese Coast Guard vessels in disputed waters (Morrison and Tang, 2012). Some additional purchases may have been made for speculative reasons as speculators looked to make a profit off of the rapidly rising rare earth prices.

We do not attempt to capture all of these reasons for the historical inventory build endogenously in the model; instead, the historical inventory build is imposed as an input to the model, with adjustable parameters representing the size and timing of the build. Because the size and timing parameters are unknown, we chose these values to calibrate the model to historical prices. The 
historical and projected $\mathrm{Nd}$ and Dy inventories held by magnet producers are shown in Figure 13. These reflect a combination of the exogenous inputs described in Section 3.1 and expected production levels that are based on an exponentially weighted moving average of past production. During the historical inventory build, rare earth purchases are $57 \%$ higher than they would have been without it (an average increased purchase rate of 9,311 tonnes/year for Nd metal and 708 tonnes/year for Dy metal). Purchases are decreased to $13 \%$ below normal levels during the drawdown. Beyond that point, projected inventories are a constant portion of expected production.
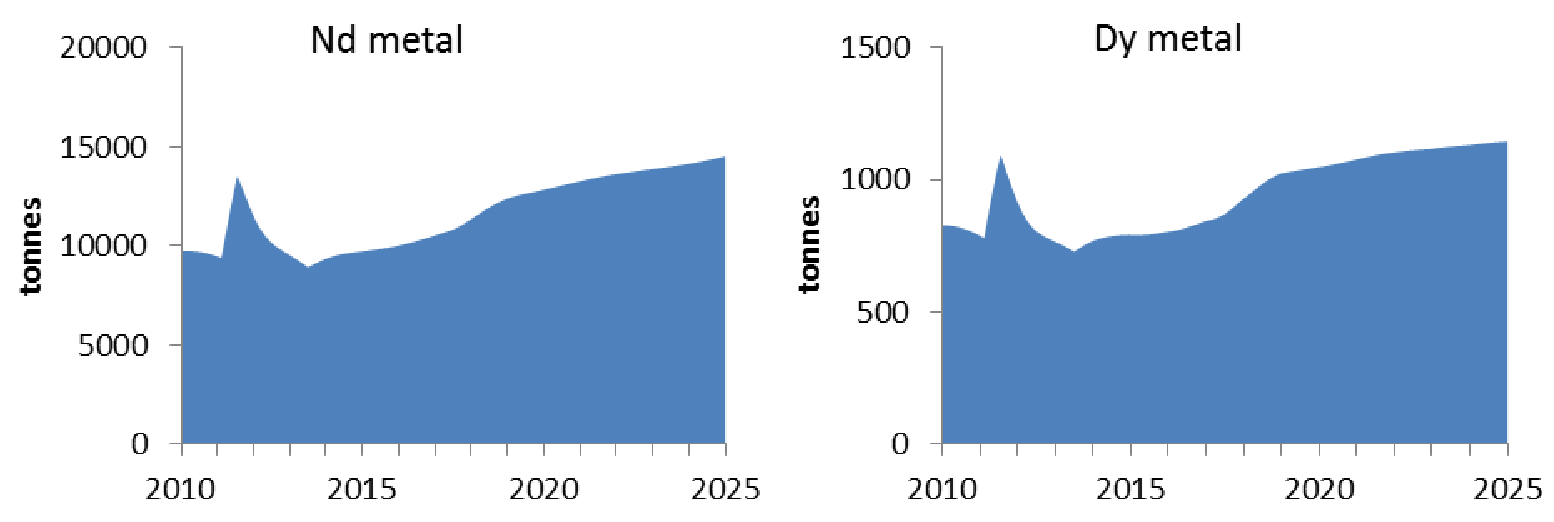

Figure 13. Nd and Dy metal inventories held by magnet makers: average baseline scenario projections.

While inventory purchases are not the only possible explanation for the 2011 price spike, our ability to accurately replicate historical prices using a plausible pattern of inventory builds and drawdowns provides support for the argument that the inventory build was a key driver of the price spike. All of the stakeholders we consulted during our stakeholder review process found the inventory builds we presented to be plausible, and some provided additional evidence supporting the pattern of significant inventory builds during the period of rising prices and inventory drawdowns while prices were falling. We were not able to replicate the historical data nearly as accurately with alternative explanations, such as a direct impact of Chinese supply reductions and export restrictions, a response to changes in final demand, or a response to deposit development patterns.

\subsubsection{Relationship between $\mathrm{Nd}$ and Dy}

A key feature of rare earth markets is the complex interdependencies and relationships among the different rare earths, in terms of both supply and demand. This is particularly true for $\mathrm{Nd}$ and Dy, because they are both produced and consumed together.

Recent price patterns for Nd and Dy have been similar: in both cases, prices were at historic lows in late 2003, rose through 2007 and into 2008, fell from 2008 to 2009, shot up in 2010 and 2011, and then fell from August 2011 through the first half of 2013. With demand and supply tied together, it is not surprising that prices often move together. In the period from 2006-2008, the demand for $\mathrm{NdFeB}$ magnets was growing at double-digit rates; in 2008, the financial market collapse led to a global reduction in demand; and in 2010-2011, China reduced its export and production quotas and strengthened environmental policies. All of these developments affected both $\mathrm{Nd}$ and Dy prices. 
Many analysts, however, have predicted a divergence between the supply of heavy rare earths, such as Dy, and light rare earths, such as Nd (e.g., Hykawy et al., 2010; Hatch, 2011). New sources of supply that are coming online are high in light rare earths, while little new production of heavy rare earths is likely to be available for a number of years. A projected increase in demand for hybrid and electric vehicles could also spur faster demand growth for Dy than for $\mathrm{Nd}$, because vehicle drives have historically required magnets with high Dy contents. On the other hand, several recent technological developments have enabled a reduction in the Dy content of magnets, making Dy demand more flexible than Nd demand. Depending on the relative importance of these developments, an imbalance could develop in either direction, leading to a divergence between Dy and Nd prices. A key goal of this modeling exercise has been to understand these dynamics and evaluate when $\mathrm{Nd}$ and Dy prices move together and when they could diverge.

The baseline model provides some insights into this question. The price patterns of 2010-2012 are caused primarily by two factors that influence both $\mathrm{Nd}$ and Dy: reductions in rare earth production by China and a buildup and draw down of inventories in all rare earths. Because both these developments apply equally to $\mathrm{Nd}$ and $\mathrm{Dy}$, it is not surprising that $\mathrm{Nd}$ and Dy prices follow similar trajectories during this period. However, beginning in 2013, modeled price paths begin to diverge significantly, with Dy prices rising while Nd prices continue falling. This divergence is driven primarily by the development of the Mountain Pass and Mount Weld mines, which contain mostly light rare earths. New supplies of heavy rare earths are projected to begin coming online in late 2017, which causes Dy prices to turn lower while Nd prices rise slightly.

\subsection{Alternative scenarios}

Additional insights can be gained by analyzing multiple scenarios to observe the impact of changing model assumptions. We examine two different changes to the baseline model: one that applies equally to $\mathrm{Nd}$ and Dy and one that has a different impact on each.

The first set of alternative scenarios examines the impact of increasing demand growth across the board relative to the baseline. The baseline results are compared with two alternative scenarios, one with $1 \%$ faster demand growth each year than the baseline and one with $2 \%$ faster demand growth each year than the baseline. The faster demand growth is applied to all application categories used in the model (onshore and offshore wind turbine demand, EV/PHEV/HEV demand, electric bike demand, and other magnet demand).

The second set of alternative scenarios explores the impact of reducing the Dy content of magnets, with the amount of reduction increasing linearly over the course of the model run. The baseline results are compared to two alternative scenarios, one with 25\% lower Dy content than the baseline by 2025 and one with 50\% lower Dy content than the baseline by 2025 . These Dy content reductions are applied to non-clean-energy applications only, because the Dy content of clean energy applications is set endogenously. Reductions in Dy content such as these could reasonably occur as new technologies are adopted that either allow magnets to achieve the same hightemperature performance with lower amounts of Dy or allow application technologies to operate at lower temperatures (DOE, 2011; Seo and Morimoto, 2014). It should be noted that the Nd content of magnets is held constant in these scenarios. In practice, when the Dy content of a magnet 
decreases, the Nd content will be increased to compensate. However, we chose to leave this out in order to isolate the impacts on market outcomes of changing only the Dy content.

\subsubsection{Increased demand growth}

Figures 14 and 15 show the impacts of increasing demand growth rates on Dy and Nd oxide price and demand. The results are largely as expected: $\mathrm{Nd}$ and Dy oxide demands increase, leading to a rise in $\mathrm{Nd}$ and Dy oxide prices. However, two less-expected results are worth highlighting. First, the impact on prices is stronger than the impact on model demand. While the BAU demand inputs are significantly different, there is much less impact on model demand once the price responses are accounted for, especially in the case of Dy. Second, Nd prices do not change much until after 2020. Up to that point, there is excess production capacity for $\mathrm{Nd}$, and the market can handle the increase in demand without any increase in price. After 2020, the faster demand growth causes demand to start catching up with production capacity, and $\mathrm{Nd}$ prices rise before new production can come online. This late rise in $\mathrm{Nd}$ prices is similar to what was found for Dy in the baseline model. 

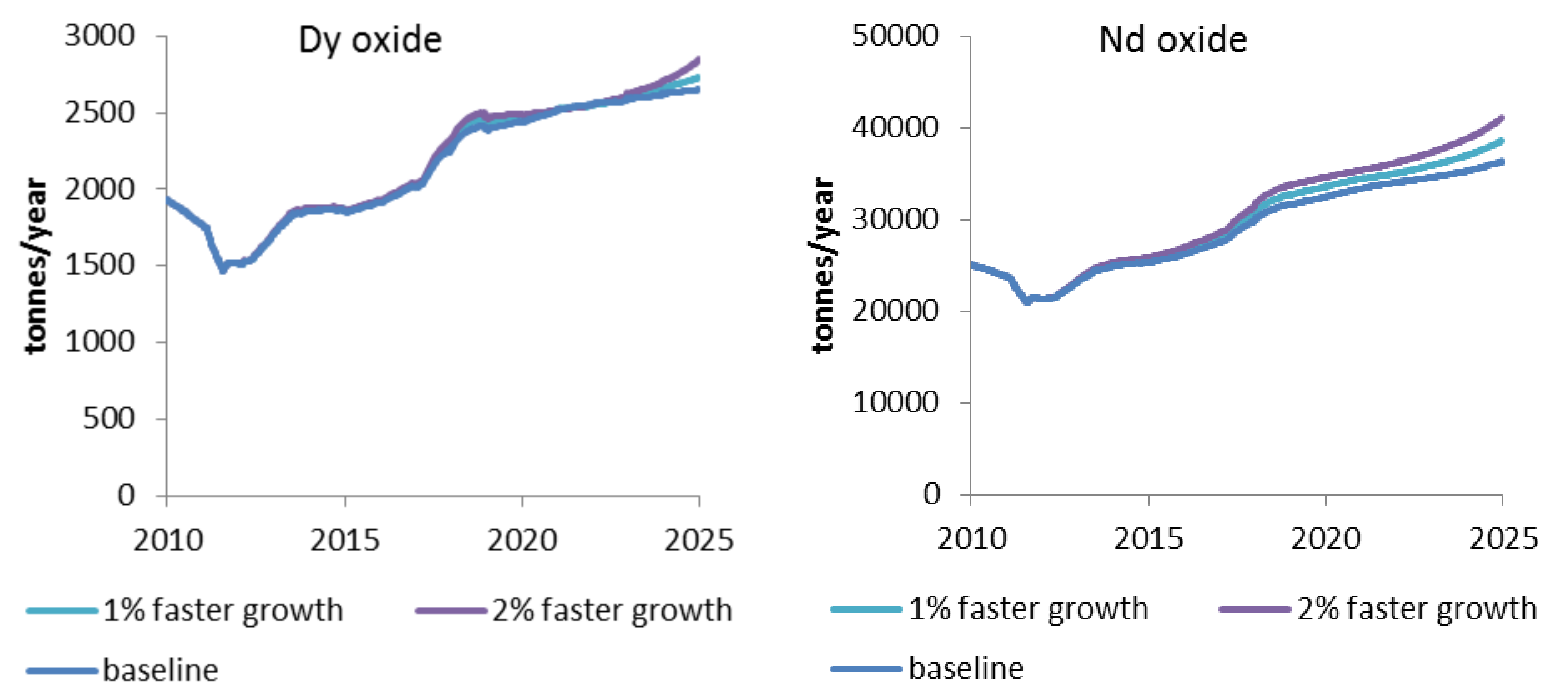

Figure 14. $\mathrm{Nd}$ and Dy oxide demands in alternative demand growth scenarios.
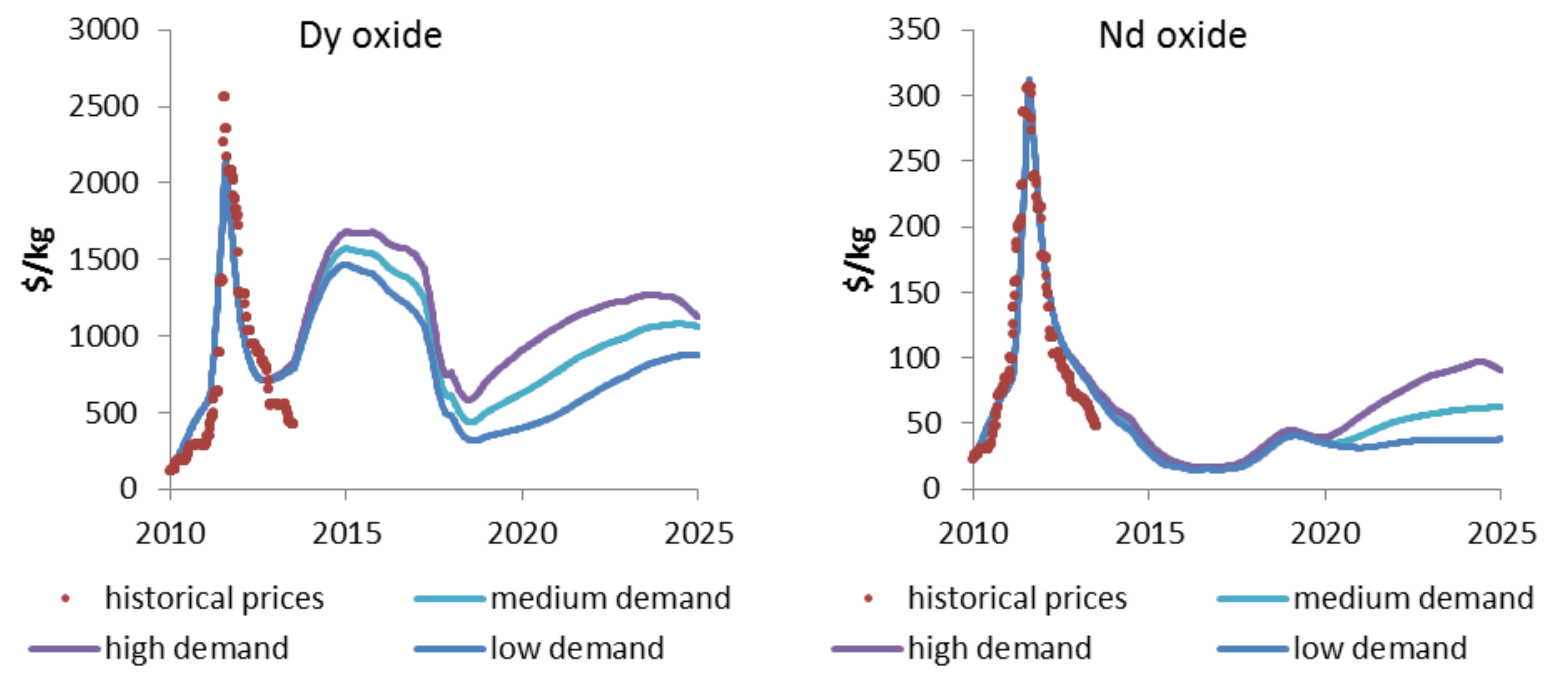

Figure 15. Nd and Dy oxide prices in alternative demand growth scenarios.

\subsubsection{Reduced Dy content}

Figures 16 and 17 show the impacts on Dy and Nd oxide prices and demand that result from reducing the Dy content of magnets. In the scenarios with reduced Dy content, both the demand and price trajectories for Dy and Nd shift in opposite directions. The drop in Dy demand and prices is easiest to explain: reducing the Dy content of magnets reduces Dy demand, which drives down prices. As Dy prices and content are reduced, the cost of purchasing Dy for magnet production is also reduced, which translates into lower magnet prices. The lower prices raise the demand for magnets and therefore the demand for $\mathrm{Nd}$, which drives up the price of $\mathrm{Nd}$. The result is that, in the reduced-Dy-content scenarios, price patterns after 2020 are reversed from the baseline scenario, with Dy prices staying flat while Nd prices rise. 
There are exceptions to this general pattern. The demand for Dy is barely reduced in the low-Dycontent scenarios until 2017 because the drop in Dy prices is sufficient to increase magnet demand. The increased demand for magnets is enough to offset the drop in Dy content. Dy demand is constrained by limited supplies during this period and, as a result, prices adjust to the change in Dy content much more than demand. This pattern reverses starting in 2018. After that point, there is adequate supply in the baseline scenario and excess supply in both the reduced-Dy-content scenarios. As a result, Dy prices are near their minimum in both reduced-Dy-content scenarios. With low Dy prices in both scenarios, there is not much difference in magnet costs, and therefore, not much difference in magnet demand or Nd prices. However, Dy demand is reduced substantially, because the reduced Dy content is not offset by a price response.
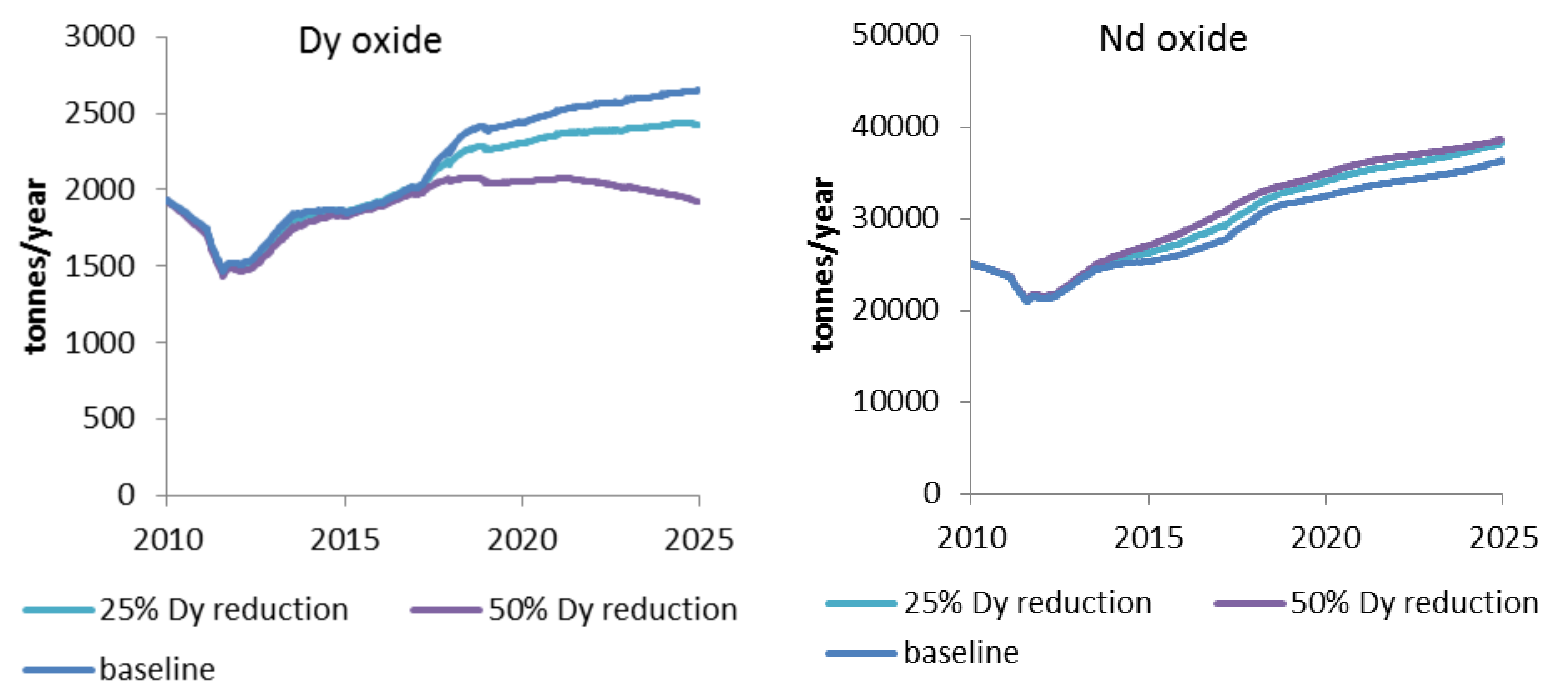

Figure 16. Nd and Dy oxide demands in alternative Dy content scenarios. 


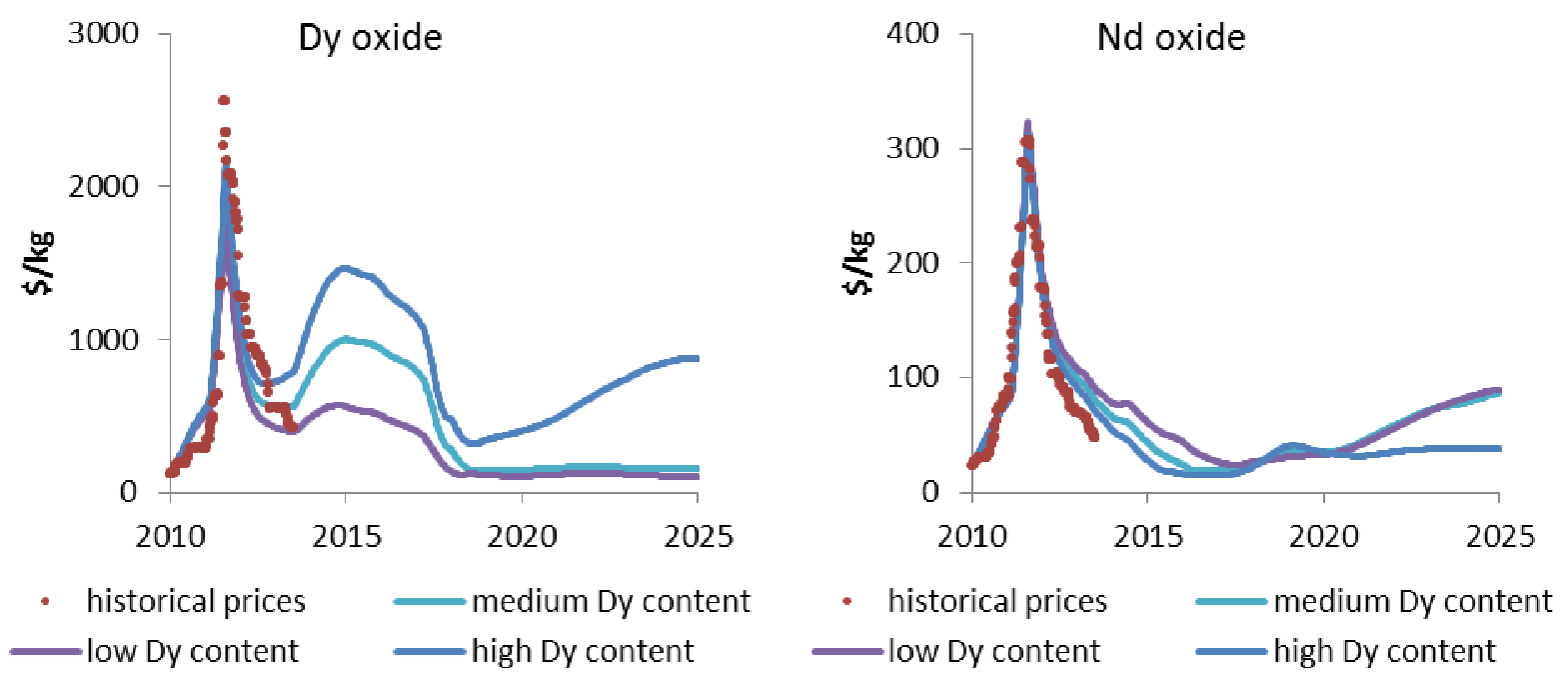

Figure 17. Nd and Dy prices in alternative Dy content scenarios.

\section{CONCLUSIONS}

This paper describes a new, dynamic, agent-based simulation model, GCMat, which can capture the relevant system complexities of global rare earth supply chains. We demonstrate GCMat's ability to evaluate critical materials markets, specifically the $\mathrm{Nd}$ and Dy markets relative to the wind turbine and vehicle industry. We analyze a number of plausible scenarios using the model, including a baseline scenario (tied to a business as usual scenario for alternative energy technology adoption), two high-demand growth rate scenarios, and two scenarios in which the Dy content of magnets is reduced as a result of technology innovation.

The GCMat model has allowed us to develop insights into the dynamics and plausible future possibilities for the rare earth market. Specifically, the model results show that there are sufficient new supplies of $\mathrm{Nd}$ and Dy under development to eventually surpass demand, but marginal deposits under development may not reach full production if market conditions do not remain favorable. Technological developments to reduce the number and Dy content of magnets used in hybrid and electric vehicle motors could play an important role in limiting the long-run growth of $\mathrm{Nd}$ and especially Dy demand. Nd supply could be tighter than Dy supply in the long run if the Dy content of magnets is reduced sufficiently, as current trends suggest is possible. Cycles in deposit development activity could eventually lead to a resurgence in prices of $\mathrm{Nd}$, Dy, or both. A resurgence in prices was observed for Dy in the baseline scenario, for both Dy and Nd in the highdemand scenarios, and for $\mathrm{Nd}$ in the reduced-Dy-content scenarios. We also found that the dramatic swings in historical prices of the materials can be explained by an inventory buildup driven by concerns over Chinese exports.

Another key model finding is that the Dy supply is likely to be tighter than the Nd supply in the short run, which could be reflected in higher prices for Dy relative to Nd. However, the up-turn in Dy prices predicted by the model in late 2013 and 2014 has not been observed yet in real world 
prices. This is likely because not all of the factors that caused the modeled price increase - the end of the inventory draw-down, the resurgence in demand, and the lack of new supply - have come to pass. One possible explanation is that demand may not have rebounded as much as predicted by the model, because much of the demand that was destroyed by the 2011 price spike has not returned as prices have fallen. GCMat does not currently include asymmetric demand responses to rises and falls in prices, but this could be explored in future versions of the model. Other possible explanations could be that Dy users have continued to draw down their inventories, or that Chinese production has increased. The model could be used to explore alternative explanations, and evaluate their implications for future market developments.

The agent-based modeling approach used in GCMat has been useful in exploring the behaviors of market participants interacting in a global market. Modeling decision making at the individual market participant level allows greater insight into how the decision rules used within each segment of the supply chain affect the overall critical materials market. Because GCMat can model causal dynamics and provide fine-grain representation of agents and their decisions, it has provided explanations for turning points in market conditions that are not otherwise available from other modeling approaches. Nonetheless, the model has a number of shortcomings, which we hope to address in future work. There are uncertainties about key data elements, such as historical production, demand and pricing, uncertainties about time frames for deposit development and new technology deployment, and uncertainties regarding agent strategies. These uncertainties can be assessed and quantified by extending model sensitivity analysis using formal design of experiments to identify model inputs and parameters that have the greatest impact on GCMat outcomes, and propagating uncertainty in input data and model parameters to model results. Another model shortcoming is that magnet producer inventory builds and future Chinese production are currently exogenously specified assumptions. In future work, inventory strategies could be endogenously modeled as dynamic responses to market conditions and government agents could be created with more complex strategies, which will allow us to endogenously determine government actions under multiple scenarios for government goals and strategies. Agents are currently aggregated at several stages of the supply chain, and parameters such as the minimum time it takes to develop a deposit are set to a fixed value, and do not vary between agents or countries. In future work, agents at all levels of the supply chain could be disaggregated, and agent strategies and parameters can be varied between agents based on agent locations or other characteristics. Demand categories besides wind turbines and electric vehicles are currently aggregated and show less complex responses to price signals than for the clean energy technologies. These categories could be disaggregated and modeled in more detail in future work. The pricing rule for other rare earths besides $\mathrm{Nd}$ and Dy is not able to capture separate demand and supply developments for each rare earth. In future work, the demand and supply of additional rare earths could be added to the model, which would generate more accurate price dynamics for these rare earths.

We also hope to extend the model and conduct additional analysis. Potential future research includes evaluating (1) the impacts of rapid clean energy development on rare earth markets, (2) the impacts of contract purchasing (by allowing agents to establish various types of contracts for the purchases of rare earths and other products), (3) vertical integration of the supply chains, and 
(4) recycling of critical materials. In addition, GCMat may be applied to other materials and supply chains.

\section{ACKNOWLEDGEMENTS}

This work is supported by DOE under contract number DE-AC02-06CH11357. The data and views expressed in this paper are those of the authors and are not endorsed by the U.S. Department of Energy or the United States government. The sponsor has played an important role in study design, collection of data, model development, results analysis and writing. We would like to thank Matthew Hart and Jennifer Li for their work on data compilation and analysis. We would like to thank several anonymous stakeholders for their review and evaluation of model assumptions and results and for their suggestions for improvements.

\section{REFERENCES}

Adamas Intelligence, 2013. Sifting the Winners from the Losers amidst the Impending Rare Earth Industry Shakeout (Includes Rare Earth Project Profiles).

Alonso, E., 2010. Material Scarcity from the Perspective of Manufacturing Firms: Case Studies of Platinum and Cobalt. PhD diss., Massachusetts Institute of Technology.

Alonso, E., Sherman, A.M., Wallington, T.J., Everson, M.P., Field, F.R., Roth, R., and Kirchain, R.E., 2012. Evaluating rare earth element availability: A case with revolutionary demand from clean technologies. Environ. Sci. Technol.46(6), 3406-3414.

Andriamasinoro, F., and Angel, J.-M., 2012. Artisanal and small-scale gold mining in Burkina Faso: Suggestion of multi-agent methodology as a complementary support in elaborating a policy. Resour. Policy, 37(3), 385-396.

Benecki, W.T., 2013. The Permanent Magnet Market - 2015. Magnetics 2013 Conference presentation, February 7-8, Orlando, Florida. From: < http://waltbenecki.com/presentations.html> (accessed May 19, 2014).

Boyd, D.W., Phillips, R.L. and Regulinski, S.G, 1982. A model of technology selection by cost minimizing producers. Manage. Sci., 28(4), 418-424.

Dent, P.C., 2012. Rare earth elements and permanent magnets (invited). J. Appl. Phys. 11 07A721.

Global Wind Energy Council (GWEC), 2011. Global Wind Report, Annual Market Update 2010.

From: < http://www.gwec.net/publications/global-wind-report-2 $\geq$ (accessed June 3, 2014).

GWEC, 2012. Global Wind Report, Annual Market Update 2011. From: < http://www.gwec.net/publications/global-wind-report-2 $\geq$ (accessed June 3, 2014).

GWEC, 2013. Global Wind Report, Annual Market Update 2012. From: < http://www.gwec.net/publications/global-wind-report-2 $\geq$ (accessed June 3, 2014). 
Hatch, G.P., 2011. Critical rare earths: global supply and demand projections and the leading contenders for new sources of supply. Tech. Metals Research. From: <http://www.techmetalsresearch.com> (accessed August 18, 2011).

Hatch, G.P., and Lifton, J., 2012. The TMR Advanced Rare-Earth Projects Index \& The TMR Rare Earths Boot Camp DVD Set, Free Handout from the Online Webinar.

Hatch, G.P., 2013. The Impending Shakeout in the Rare Earth Sector: Who Will Survive? From: <http://www.techmetalsresearch.com/2013/09/the-impending-shakeout-in-the-rare-earthsector-who-will-survive/ $\geq$ (accessed May 19, 2014).

Humphries, M., 2013. Rare Earth Elements: The Global Supply Chain. Congressional Research Service 7-5700.

Hykawy, J., Thomas, A., and Casasnovas, G., 2010. The Rare Earths: Pick Your Spots CAREFULLY. Rep. Byron Capital Markets. From: <http://www.byroncapitalmarkets.com/wpcontent/uploads/2011/02/Rare-Earth-Elements-Industry-Report-03-25-2010.pdf> (accessed November 4, 2013).

International Energy Agency (IEA), 2013. Tracking Clean Energy Progress 2013: IEA Input to the Clean Energy Ministerial. From: <http://www.iea.org/etp/tracking/> (accessed November 4, 2013).

Kingsnorth, D., 2013. Rare Earths: Is Supply Critical in 2013? Presentation for AusIMM 2013 Critical Minerals Conference, June 4-5, Perth, Australia.

Labys, W.C., 1978. Bibliography of commodity models, in: F.G. Adams and J.R. Behrman (Eds.), Econometric Modeling of World Commodity Policy, Lexington.

Macal, C. M., and Hill, L.G., 1985. Metal price and supply effects of electric vehicle commercialization, Resour. Energ. 7(3): 259-282.

Macal, C.M., and North, M.J., 2010. Tutorial on agent-based modeling and simulation. J. Simul. 4(3): 151-162, September.

Massari, S., and Ruberti, M., 2013. Rare earth elements as critical raw materials: focus on international markets and future strategies. Resour. Policy, 38(1), 36-43.

Merriman, D., 2013. A Review of the Global Supply of Rare Earths. Roskill Information Services Presentation for Royal Society of Chemistry, Environmental Chemistry Group. From: <http://www.rsc.org/images/David-Merriman_tcm18-230229.pdf> (accessed May 19, 2014).

Metal-Pages, 2013. From: <http://www.metal-pages.com/metalprices/rareearths> (accessed July 15, 2013).

Morrison, W.M., and Tang, R., 2012. China's rare earth industry and export regime: economic and trade implications for the United States. Congressional Research Service 7-5700 R42510. 
North, M. J., Collier, N.T., Ozik, J., Tatara, E.R., Macal, C.M., Bragen, M., Sydelko, P., 2013. Complex adaptive systems modeling with Repast Simphony, Com. Adap. Sys. Model. 1:3, doi:10.1186/2194-3206-1-3, April.

Salant, S.W., 1982. Imperfect competition in the international energy market: a computerized NashCournot model, Oper. Res. 30(2): 252-280.

Seo, Y., and Morimoto, S., 2014. Comparison of dysprosium security strategies in Japan for 20102030. Resour. Policy, 39, 15-20.

Shaw, S. and Chegwidden, J., 2012. Global drivers for rare earth demand. Roskill Information Services.

Shih, J., Linn, J., Brennan, T.J., Darmstadter J., Macauley, M.K., and Preonas, L., 2012. The supply chain and industrial organization of rare earth materials: implications for the U.S. wind energy sector. Resources for the Future. From: <www.rff.org/RFF/Documents/RFF-Rpt-Shih etal RareEarthsUSWind.pdf> (accessed May 19, 2014).

Takayama, T., and G. G. Judge., 1971. Spatial and Temporal Price and Allocation Models, NorthHolland, Amsterdam.

Technology Metals Research (TMR), 2012. TMR Advanced Rare-Earth Projects Index. From: $<$ http://www.techmetalsresearch.com/metrics-indices/tmr-advanced-rare-earth-projectsindex/> (accessed 8/10/2012).

U.S. Department of Energy (DOE), 2010. Critical Materials Strategy. United States Department of Energy report. From: <http://energy.gov/node/206101> (accessed May 19, 2014).

DOE, 2011. Critical Materials Strategy. United States Department of Energy report. From: <http://energy.gov/node/349057> (accessed May 19, 2014).

U.S. Geological Survey (USGS), 2013a. 2011 Minerals Yearbook: Rare Earths [Advanced Release]. From: <http://minerals.usgs.gov/minerals/pubs/commodity/rare_earths/> (accessed May 19, 2014).

USGS, 2014. Mineral Commodity Summaries, January 2013: Rare Earths. From: <http://minerals.usgs.gov/minerals/pubs/commodity/rare_earths/> (accessed November 5, 2014).

Wübbeke, J., 2013. Rare earth elements in China: Policies and narratives of reinventing and industry. Resour. Policy, 38, 384-394. 